\title{
An assessment of Indian monsoon seasonal forecasts and mechanisms underlying monsoon interannual variability in the Met Office GloSea5-GC2 system
}

Article

Accepted Version

Johnson, S. J., Turner, A., Woolnough, S., Martin, G. and MacLachlan, C. (2017) An assessment of Indian monsoon seasonal forecasts and mechanisms underlying monsoon interannual variability in the Met Office GloSea5-GC2 system. Climate Dynamics, 48 (5). pp. 1447-1465. ISSN 1432-0894 doi: https://doi.org/10.1007/s00382-016-3151-2 Available at https://centaur.reading.ac.uk/51265/

It is advisable to refer to the publisher's version if you intend to cite from the work. See Guidance on citing.

To link to this article DOI: http://dx.doi.org/10.1007/s00382-016-3151-2

Publisher: Springer

All outputs in CentAUR are protected by Intellectual Property Rights law, including copyright law. Copyright and IPR is retained by the creators or other copyright holders. Terms and conditions for use of this material are defined in the End User Agreement. 


\section{www.reading.ac.uk/centaur}

\section{CentAUR}

Central Archive at the University of Reading

Reading's research outputs online 


\title{
An assessment of Indian monsoon seasonal forecasts and mechanisms underlying monsoon interannual variability in the Met Office GloSea5-GC2 system
}

\author{
Stephanie J. Johnson, Andrew Turner, Steven Woolnough, Gill Martin, \\ Craig MacLachlan
}

Received: date / Accepted: date

\begin{abstract}
We assess Indian summer monsoon seasonal ${ }_{26}$ forecasts in GloSea5-GC2, the Met Office fully coupled ${ }_{27}$ subseasonal to seasonal ensemble forecasting system. 28 Using several metrics, GloSea5-GC2 shows similar skill ${ }_{29}$ to other state-of-the-art forecast systems. The predic- 30 tion skill of the large-scale South Asian monsoon circulation is higher than that of Indian monsoon rain- ${ }^{31}$ fall. Using multiple linear regression analysis we evalu- ${ }^{32}$ ate relationships between Indian monsoon rainfall and five possible drivers of monsoon interannual variability. Over the time period studied (1992-2011), the El Niño- ${ }_{33}$ Southern Oscillation (ENSO) and the Indian Ocean dipole (IOD) are the most important of these drivers ${ }_{34}$ in both observations and GloSea5-GC2. Our analysis ${ }_{35}$ indicates that ENSO and its teleconnection with the 36 Indian rainfall are well represented in GloSea5-GC2. ${ }_{37}$ However, the relationship between the IOD and Indian ${ }_{38}$ rainfall anomalies is too weak in GloSea5-GC2, which ${ }_{39}$ may be limiting the prediction skill of the local mon- 40 soon circulation and Indian rainfall. We show that this ${ }_{41}$ weak relationship likely results from a coupled mean ${ }_{42}$ state bias that limits the impact of anomalous wind ${ }_{43}$ forcing on SST variability, resulting in erroneous IOD $_{44}$ sst anomalies. Known difficulties in representing con- ${ }_{45}$ vective precipitation over India may also play a role. ${ }_{46}$
\end{abstract}

S. Johnson · A. Turner $\cdot$ S. Woolnough 48 National Centre for Atmospheric Science - Climate direc- ${ }^{49}$ torate

Department of Meteorology, University of Reading, Earley ${ }_{51}$ Gate, Reading RG6 6BB, UK

E-mail: s.j.bush@reading.ac.uk Present address of S. John- ${ }^{52}$ son: ECMWF, Shinfield Park, Reading, RG2 9AX, UK 53

G. Martin · C. MacLachlan

Met Office Hadley Centre, FitzRoy Road, Exeter EX1 3PB, 55 UK
Since Indian rainfall responds weakly to the IOD, it responds more consistently to ENSO than in observations. Our assessment identifies specific coupled biases that are likely limiting GloSea5-GC2 prediction skill, providing targets for model improvement.

Keywords Indian monsoon, seasonal forecasting, Indian Ocean dipole

\section{Introduction}

Analysis of intraseasonal and interannual modes of Indian summer monsoon rainfall variability suggests that there is a significant seasonally persisting component of Indian monsoon rainfall anomalies forced by slowly varying boundary conditions (Charney and Shukla, 1981; Krishnamurthy and Shukla, 2000, 2007). For variability in boundary conditions to be a useful source of seasonal predictability, anomalies must be large and persistent, they must interact with monsoon rainfall through a consistent physical mechanism and the response of monsoon rainfall must be large enough to distinguish from the intrinsic variability of the atmosphere (Kang and Shukla, 2006). Studies have investigated the predictability gained from many sources, including modes of sea surface temperature (SST) variability, variability of soil moisture and interannual variability of snow cover (e.g. Palmer and Anderson, 1994; Goddard et al, 2001).

For the Indian summer monsoon, the most significant and well known source of predictability is the El Niño-Southern Oscillation (ENSO, e.g. Shukla and Paolino, 1983). A developing El Niño event warms SSTs in the east Pacific, shifting the Walker circulation such that anomalous subsidence occurs over the Maritime 
Continent and Indian Ocean, reducing monsoon rain-111 fall. A developing La Niña event has the opposite effect ${ }_{12}$ (e.g. Webster and Yang, 1992; Ju and Slingo, 1995).113 Recent work suggests that the zonal location of the14 warm SSTs alters the strength of the relationship by115 altering the location of the anomalous subsidence. Cen-116 tral Pacific El Niño events are consequently more likely117 to strongly suppress monsoon rainfall than east Pacific1s El Niño events (Krishna Kumar et al, 2006).

Another important known source of predictability ${ }^{120}$ is the the Indian Ocean dipole (IOD, also known $a^{121}$ the Indian Ocean Zonal mode). The IOD is a coupled ${ }^{122}$ mode of SST variability in the equatorial Indian ocean ${ }^{123}$ analogous to ENSO in many ways. In a positive IOD ${ }^{124}$ event, anomalous easterlies develop in spring off the ${ }^{25}$ coast of Sumatra which increase upwelling, shoal the ${ }^{126}$ thermocline and create cool SST anomalies that ex-127 tend into the eastern equatorial Indian Ocean (EEIO).128 These are often accompanied by warm SST anoma-129 lies in the western equatorial Indian Ocean (WEIO).130 This changes the zonal equatorial SST gradient, and ${ }^{131}$ consequently reinforces equatorial zonal easterly wind ${ }^{132}$ anomalies. An IOD event continues to develop through ${ }^{133}$ July and August and peaks in the autumn (Saji et al,,$^{134}$ 1999; Webster et al, 1999; Annamalai et al, 2003). Us-135 ing an atmospheric GCM (AGCM), Ashok et al (2001)136 demonstrated that a positive IOD event drives anoma-137 lous low-level atmospheric convergence in the WEIO138 and divergence in the EEIO that strengthens the South ${ }^{139}$ Asian monsoon circulation, increasing rainfall over In-140 dia.

Kucharski et al $(2007,2008)$ identify a component ${ }^{142}$ of Indian monsoon interannual variability that is forced ${ }^{143}$ by the Atlantic Niño, an ENSO-like mode of SST vari-144 ability in the southeastern tropical Atlantic. Atlantic ${ }^{145}$ Niño SST anomalies extend from the Angola coast to ${ }^{146}$ the Gulf of Guinea in spring and summer (Chang et al, ${ }^{147}$ 2006). Using AGCM experiments, Kucharski et al $\left(2007^{148}\right.$ 2008) demonstrate that cool SSTs (Atlantic Niña) drive ${ }^{149}$ a stationary wave response that creates a low-level cy ${ }_{-150}$ clone over India, bringing increased moisture to India ${ }^{151}$ and increasing seasonal monsoon precipitation. $\quad{ }_{152}$

Many studies have explored the role of snow over ${ }^{153}$ Asia in driving monsoon rainfall interannual variabil- ${ }^{154}$ ity (see references in Fasullo, 2004). Sensitivity experi- ${ }^{155}$ ments in atmospheric GCMs (Turner and Slingo, 2011) and the ECMWF seasonal forecast system 4 (Senan et al, 2015), demonstrate a mechanism linking snow over the Himalayas and Tibetan Plateau (HimTP) with the timing and intensity of the Indian monsoon. They ${ }_{158}$ show that increased snow cover over the HimTP in spring and summer reduces surface sensible and long-159 wave heating as proposed by Blanford (1884), which 60 delays the onset of the monsoon and significantly reduces monsoon rainfall in June. As HimTP snow cover decreases rapidly through the spring and early summer, interannual snow variability has little impact on rainfall variability later in the monsoon season.

Despite these many sources of predictability, Indian monsoon rainfall prediction skill is modest in state-ofthe-art coupled seasonal prediction systems (Kim et al, 2012; Rajeevan et al, 2012; Nanjundiah et al, 2013). The DEMETER sample of six seasonal forecast systems had a multimodel mean interannual correlation skill of $0.28(p>0.1)$ over 1960-2001. The more recent ENSEMBLES sample, which uses updated versions of the DEMETER systems, improved to $0.45(p<0.05)$ over the slightly longer time period of 1960-2005. Mean state biases in boundary conditions, poor representation of coupled teleconnections with monsoon rainfall, large ensemble spread and the lack of seasonal predictability of intraseasonal variability are some of the challenges that face monsoon seasonal prediction (Sperber et al, 2000; Krishnamurthy and Shukla, 2007; Kim et al, 2012; Rajeevan et al, 2012; Sperber et al, 2013).

Here, we assess Indian summer monsoon seasonal forecasts in GloSea5-GC2, the Met Office fully coupled subseasonal to seasonal ensemble forecasting system. We assess the representation of the tropical mean state, the prediction skill of monsoon rainfall (all India rainfall, AIR) and representation of relationships between monsoon rainfall and ENSO, the IOD, the Atlantic Niño and HimTP snow cover. In this publication we focus on the interannual variability of monsoon rainfall; a future publication will focus on intraseasonal variability (Jayakumar et al, 2016).

In Section 2 we describe the forecast system, the integrations analysed and our analysis techniques. In Section 3 we describe the global properties of the forecast system, including mean state biases and maps of ensemble signal-to-noise ratios. In Section 4 we assess the interannual prediction skill of Indian summer monsoon rainfall. In Section 5 we use multiple regression analysis to assess the representation of relationships between AIR and sources of predictability. Where the regression analysis indicates these relationships are poorly represented, we explore the mechanisms behind these relationships in more detail, to determine the source of the errors. We conclude in Section 6.

\section{Methodology}

\subsection{GloSea5-GC2}

Full details of the GloSea5-GC2 configuration are described in Williams et al (2015), so we limit our descrip- 
tion here to a brief introduction of the componant mod-212 els. GloSea5-GC2 uses the MetUM global atmosphere213 6.0 (GA6.0) configuration at $\mathrm{N} 216$ resolution $\left(0.833^{\circ} \times 214\right.$ $0.556^{\circ}$ ) with 85 vertical levels (Walters et al, 2015). Itt215 includes a stochastic physics scheme, Stochastic Kinetic216 Energy backscatterv2 (SKEB2, Bowler et al, 2009), to217 represent unresolved stochasticity. SKEB2 introduces 218 small grid-level perturbations throughout the integra- -219 tions to create ensemble spread. The global land $6.0_{220}$ (GL6.0) configuration of JULES (Best et al, 2011; Wal-221 ters et al, 2015) with four vertical soil levels is "tightly 222 coupled" to the MetUM: integrated on the MetUM gride23 as part of the same executable. The MetUM is cou-224 $_{2}$ pled on a three-hourly time scale to ocean and sea ice 225 models using the OASIS3 coupler (Valcke, 2013). The 226 global ocean 5.0 (GO5.0) configuration of the Nucleus227 for European Modelling of the Ocean (NEMO) model 228 is integrated on the ORCA $0.25^{\circ}$ tripolar grid with $75_{229}$ vertical levels. The level thickness is a double tanh func-230 tion of depth such that the level spacing increases fromem $1 \mathrm{~m}$ near the surface to $200 \mathrm{~m}$ at $6000 \mathrm{~m}\left(_{\left(M^{2} g a n n\right.}{ }_{232}\right.$ et al, 2014). The global sea ice 6.0 configuration of the $e_{233}$ Los Alamos sea ice model (CICE) is tightly coupled $t_{234}$ NEMO on the NEMO grid (Rae et al, 2015; Megann $_{235}$ et al, 2014) and integrated with five sea-ice thickness 236 categories.

\subsection{Hindcast set}

The hindcast set we assess here is composed differently ${ }^{241}$ than the ensemble used for operational seasonal fore- ${ }^{242}$ casts and from the hindcasts used to bias correct the op- ${ }^{243}$ erational forecast. For comparison, we describe the op- ${ }^{244}$ erational forecast system before describing the dataset we use here.

In the operational forecast system, two seasonal fore $\mathrm{z}_{245}$ cast ensemble members are initialised every day and integrated for 210 days. Three weeks of ensemble mem-246 bers are combined to create the operational seasonal forecast, a total of 42 ensemble members in each fore-247 cast. These are bias corrected using a 14 year (1996-248 2009), three ensemble member hindcast set initialised 49 on the 1, 9, 17 and 25 th of each month. The four nearesteso weeks of hindcasts, a total of 12 ensemble members, are251 weighted, combined, and then used to bias correct the 252 forecasts. The GloSea5-GC2 operational forecast sys-253 tem is fully described in MacLachlan et al (2015). $\quad 254$

The hindcast set in this study contains 20 years of ${ }_{255}$ hindcasts, spanning 1992 to 2011, which are initialisedes6 on three start dates, 25 April, 1 May and 9 May. They257 are integrated for 140 days, ending on 11, 17 and 25258 September. To assess seasonal monsoon rainfall, we val-259 idate JJA values, leaving a forecast lead time of ap-260 proximately one month. For years 1992 through 1995, 2010 and 2011 eight ensemble members are initialized on each start date, resulting in 24 members for each hindcast year. For 1996 through 2009, five ensemble members are initialized on each start date, resulting in 15 members for each hindcast year.

The MetUM and JULES are initialised from daily ERA-Interim reanalysis (gridded to $0.75 \times 0.75^{\circ}$, Dee et al, 2011). JULES soil moisture is initialised from a JULES re-analysis climatological seasonal cycle of soil moisture calculated (1989 to 2011). NEMO and CICE are initialised from the GloSea5 Ocean and Sea ice analysis using the GloSea5 global ocean 3.0 system (hereafter referred to as the GloSea5-GO3 analysis), which is driven by ERA-Interim reanalysis and incorporated using the NEMOVAR data assimilation scheme (Blockley et al, 2014). NEMOVAR is based on NEMO and CICE using the same resolution and similar parametrisations as the forecast model configurations (Mogensen et al, 2009).

A climatological seasonal cycle of solar forcing is prescribed. Climate forcings such as $\mathrm{CO}_{2}$ are set to observed values until the year 2005, and subsequently follow the Intergovernmental Panel on Climate Change RCP4.5 scenarios. Other aerosols are updated every five days and use a climatological seasonal cycle derived from previous versions of the MetUM. Ozone concentrations are updated every 30 days and are set to the observational climatology of the Stratosphere-troposphere Processes And their Role in Climate (SPARC, Cionni et al, 2011) dataset (1994 to 2005). Further details are described in MacLachlan et al (2015) and Williams et al (2015).

\subsection{Analysis techniques}

\subsubsection{Multiple linear regression analysis}

To assess relationships between Indian rainfall and slowly varying boundary conditions, we perform multiple linear regression analysis. We use the "regress" function in IDL8.2 (modified version of "regres" in Bevington, 1969), which uses all independent variables to minimise the overall residual and give the best fit. We assess goodness of fit using the coefficient of determination, or $R^{2}$, value. In the case of a perfect fit, $R^{2}=1$; in the case of no relationship, $R^{2}=0$. In addition to the regression coefficients (the slopes of the regression lines) we analyse the standard error of the regression fit. The standard error is the sampling error in the regression coefficient assuming the data is normally distributed about the fit. 


\subsubsection{Forward selection of parameters}

To diagnose the relative importance of independent vari $i_{313}$ ables in our multiple regression analysis, we use for- ${ }_{-314}$ ward selection (Wilks, 2006). First, a single linear re-315 gression is calculated between the dependent variable ${ }_{316}$ and each independent variable in turn. The indepen-317 dent variable with the highest $R^{2}$ is noted. Then a two ${ }_{318}$ parameter regression is calculated using this indepen-319 dent variable and each of the remaining independent ${ }_{320}$ variables in turn. The regression with the highest $R^{2}{ }_{321}$ is kept and so on, until all independant variables have been included in the fit. The change in the $R^{2}$ value as each independent variable is added to the regression indicates the importance of each of the independent variables to the final regression.

\subsubsection{Samples of ensemble members}

To validate GloSea5-GC2 against observations, it is cru-324 cial that we do not solely analyse the ensemble mean.325 Observations contain chaotic noise as well as variability326 forced by slowly varying components of the climate sys-327 tem (e.g. Palmer and Anderson, 1994; Goddard et al,328 2001). Ensemble averaging reduces noise, reducing the ${ }^{22}$ total atmospheric variability and increasing the relative330 contribution of forced variability to the total variabil- ${ }_{331}$ ity. To accurately compare GloSea5-GC2 variability to $_{332}$ observed variability and to reduce the risk of mistak- ${ }_{333}$ ing noise in observations for forced variability, we must $_{334}$ compare individual ensemble members from the hind- ${ }_{335}$ cast set to observations. To accomplish this we repeat ${ }_{336}$ our statistical calculations, such as the regression analy- ${ }_{337}$ sis in Section 5, on many samples of ensemble members ${ }_{338}$ and compare a distribution of the resulting values, $\operatorname{such}_{33}$ as regression coefficients, to a single observed value.

In this article, most metrics require a twenty year JJA time series from the hindcast set. We create many ${ }^{341}$ JJA time series for our statistical calculations by com- $^{342}$ bining different ensemble members from different years. ${ }^{343}$ Ensemble members with the same start date are ini- ${ }^{344}$ tialised identically, so any combination ensemble mem- ${ }^{345}$ bers with the same start date can be used.

The first step is to create five time series for each of ${ }^{347}$ the start dates by randomly sampling ensemble mem- ${ }^{348}$ bers with the same start date from each hindcast year ${ }^{349}$ without replacement. In years with five members for ${ }^{350}$ each start date, each of the five ensemble members is ${ }^{351}$ used in one of these time series. In years with eight en- ${ }^{352}$ semble members for each start date, five of the eight ${ }^{353}$ members are used in these five time series. There are ${ }^{34}$ three start dates in the hindcast set, so this process ${ }^{355}$ results in 15 time series. We then repeat this process ${ }^{356}$
$N$ times. We raised $N$ until raising it further did not change the results, to $N=2000$, creating $3 \times 10^{4} \mathrm{JJA}$ time series which we refer to as "hindcast samples." In these samples, every ensemble member in the years with five ensemble members for each start date is used an equal number of times. In the years with eight ensemble members for each start date, each individual member is used fewer times and it is also possible that some members are used more than others. Given the large value of $N$ we would not expect this to affect our results.

\subsection{Observational and reanalysis datasets}

To assess precipitation we use the Global Precipitation Climatology Project (GPCP) Version 2.2 Monthly Precipitation Analysis (Adler et al, 2003). GPCP is a $2.5^{\circ}$ gridded merged analysis that incorporates precipitation estimates from low-orbit satellite microwave data, geostationary satellite infrared data and surface rain gauge observations. GloSea5-GC2 data are bilinearly interpolated to the GPCP grid for comparison.

We assess winds using the European Centre for MediumRange Weather Forecasts (ECMWF) ERA-Interim atmospheric reanalysis product gridded to $0.70 \times 0.70^{\circ}$ (Dee et al, 2011). Fields were interpolated to the MetUM grid and compared on equivalent pressure levels. We assess snow using snow water equivalent (snow mass) from ERA-Interim/Land, a global land surface reanalysis dataset driven by ERA-Interim (Balsamo et al, 2015), which is also interpolated to the MetUM grid for comparison.

SST is assessed using the GloSea5-GO3 analysis used to initialise the NEMO ocean model, as described in Section 2.2, interpolated to the MetUM grid. The ocean temperature profile is assessed using the EN4.1.1 analyses $\left(1^{\circ} \times 1^{\circ}\right.$, Good et al, 2013). This analysis includes ocean temperature and salinity profiles from many sources, including the Global Temperature and Salinity Profile Program and the Argo dataset, which are quality controlled before creating the analysis. An updated version of the Gouretski and Reseghetti (2010) bias correction is then applied. Profiles are compared on their native levels.

All fields are compared over 1992 to 2011. In the rest of this paper, when a combination of observations and reanalysis are used to validate the model they will be collectively referred to as "observations." 

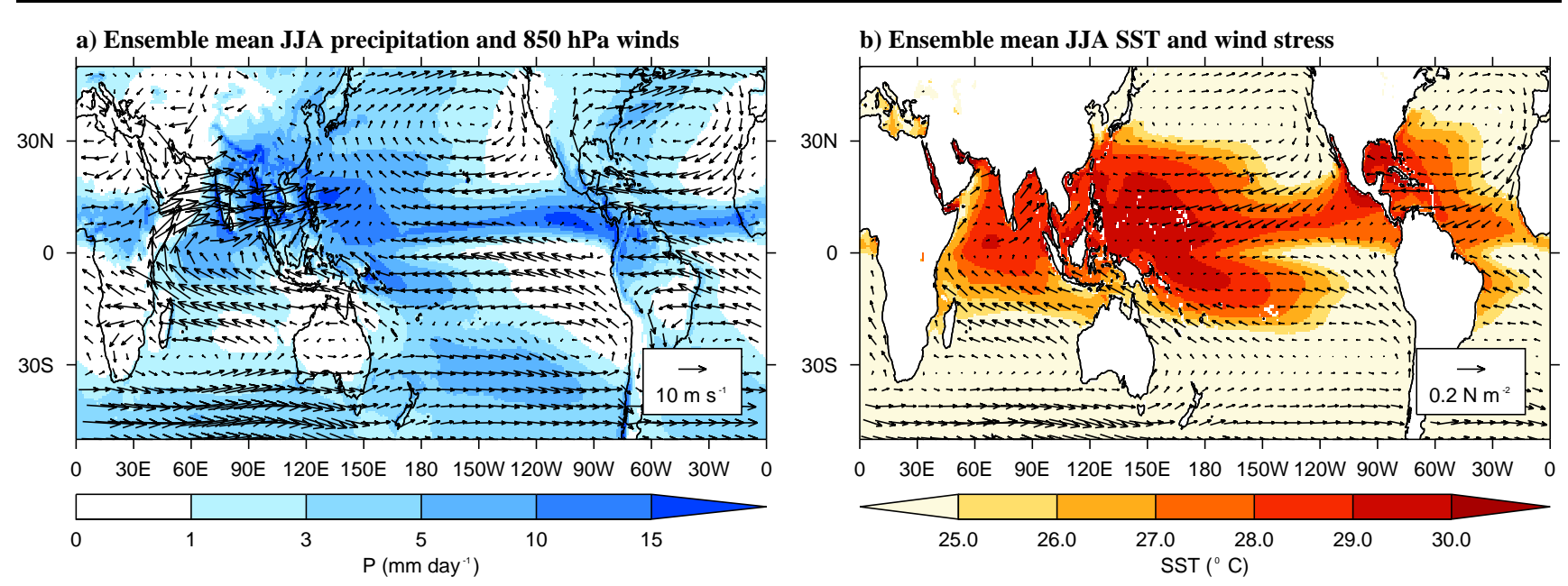

c) Ensemble mean JJA precipitation and $850 \mathrm{hPa}$ winds bias
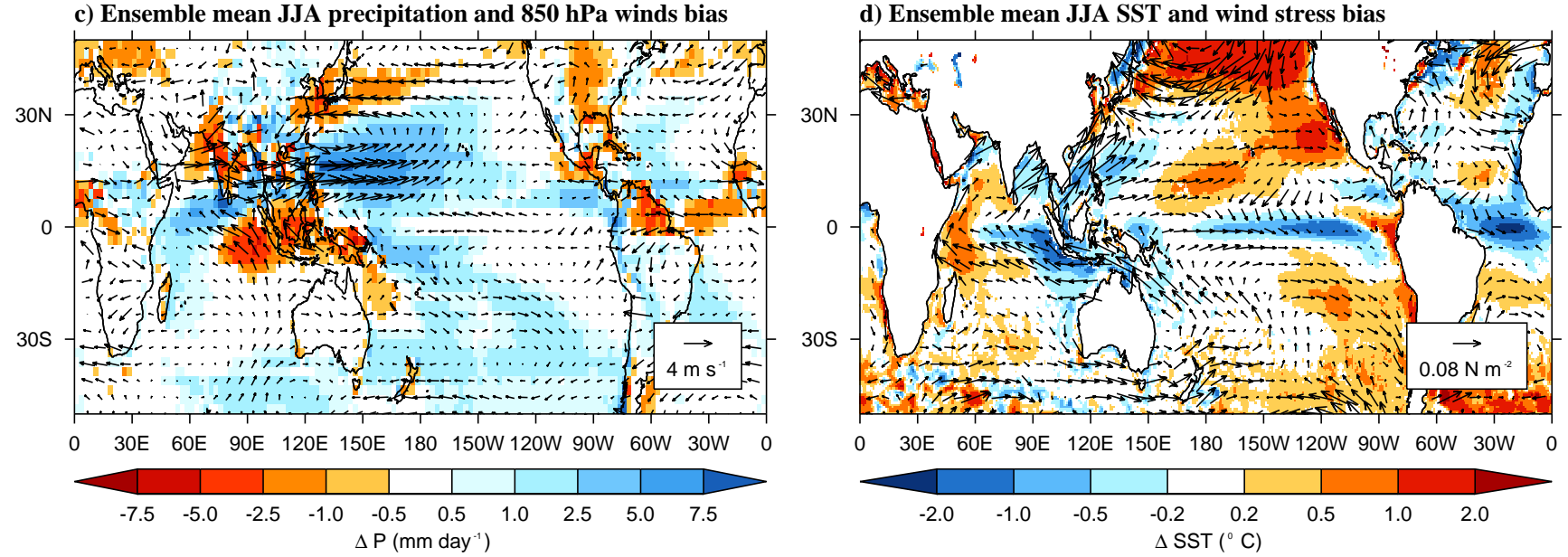

Fig. 1 Ensemble mean JJA (a) precipitation and $850 \mathrm{hPa}$ winds in GloSea5-GC2, (b) SST and surface wind stress in GloSea5GC2, (c) precipitation and $850 \mathrm{hPa}$ winds bias with respect to GPCP and ERA-Interim, (d) SST and surface wind stress bias with respect to GloSea5-GO3 analysis and ERA-Interim.

\section{Forecast system global performance}

\subsection{Ensemble mean bias}

The GloSea5-GC2 ensemble mean JJA precipitation and $850 \mathrm{hPa}$ winds are shown in Figure 1a alongside $\mathrm{e}_{381}^{380}$ their bias with respect to GPCP and ERA-Interim in ${ }_{382}^{381}$ Figure 1c. Precipitation biases in the Indo-Pacific $\operatorname{ar}_{383}^{382}$ similar to those seen in the CMIP5 models (Sperber ${ }_{384}$ et al, 2013) and state-of-the-art seasonal forecast sys- ${ }_{385}$ tems (Rajeevan et al, 2012; Kim et al, 2012), with ex- ${ }_{385}$ cess precipitation over the WEIO and western north ${ }_{387}^{386}$ Pacific and a deficit of precipitation over India, the ${ }_{388}$ Maritime Continent and the EEIO. The deficit of pre- ${ }_{389}$ cipitation over India (AIR deficit of $\left.0.72 \mathrm{~mm} \mathrm{day}^{-1}\right)_{390}^{389}$ is largely due to a climatologically late onset of the monsoon in GloSea5-GC2, which reduces the precipitation over and around India in May and June. Precip-392 itation is similar to the observed climatology in July393 and August (not shown). Monsoon westerlies, whichs94 Arabian Sea cold bias than is generally seen in the CMIP5 models (Levine et al, 2013). The well documented Arabian Sea cold SST bias in coupled GCMs tends to weaken the monsoon circulation and monsoon precipitation, but initialisation in May prevents the growth of a large bias (Levine and Turner, 2012; Levine et al, 2013, personal communication R. Levine). The excess precipitation bias in the western north Pacific seen in GloSea5-GC2 is also associated with the cyclonic wind bias over the western north Pacific and east Asia (Bush et al, 2015).

GloSea5-GC2 JJA SST and wind stress are shown alongside their biases in Figure 1b and Figure 1d. The eastern side of each ocean basin shows an equatorial 
cold bias. Equatorial cold biases are common in cou-443 pled models (e.g. Li and Xie, 2012, 2014) and seasonah44 forecast systems (Kim et al, 2012; Vanniere et al, 2013),445 especially in the Pacific. GloSea5-GC2 also has a cold 446 SST bias associated with the western north Pacific ex-447 cess precipitation bias and a warm bias in the west-448 ern Indian Ocean opposite the cold bias in the EEIO ${ }_{449}$ Large wind stress biases are associated with many of 450 the cold SST biases in the warm pool region, including g $_{41}$ the EEIO, Bay of Bengal, South China Sea and western north Pacific. We address how these Indian Ocean biases may be impacting the monsoon rainfall forecasta52 skill in Section 5.2.2.

\subsection{Ensemble spread}

To quantify the ensemble spread in the forecast system, we calculate the signal-to-noise ratio $(S / N)$ of $\mathrm{JJA}_{456}^{457}$ anomalies, defined as the ratio of the variance of the ensemble mean anomaly time series to the average vari- ${ }_{460}$ ance of the ensemble member anomalies in each year (Rowell et al, 1995; Kang and Shukla, 2006). If $S / N>1_{462}$ then the interannual variability in the ensemble mean ${ }_{463}$ is greater than the average ensemble spread. In Figure 2 we show $S / N$ maps for JJA precipitation and ${ }_{465}$ zonal vertical wind shear $(850-200 \mathrm{hPa})$, which is a di- ${ }_{466}$ agnostic of the large-scale monsoon circulation related $d_{467}^{466}$ to the strength of the monsoon diabatic heating (Gill, 1980; Webster and Yang, 1992). In both metrics, there is lower $S / N$ in the Indian Ocean than in the other ocean basins. JJA precipitation $S / N>1$ is $\operatorname{confined}_{471}^{470}$ to the equatorial Pacific and Maritime Continent, in- ${ }_{472}$ dicating that the precipitation anomalies most directly forced by ENSO SST anomalies have the highest $S / N_{474}^{473}$

$S / N$ can also be expressed as a theoretical limit ${ }_{475}$ on the correlation skill, using the expression $R_{\text {limit }}={ }_{476}$ $\sqrt{\frac{S / N}{S / N+1}}$ (Kang and Shukla, 2006). A $R_{\text {limit }}=0.5$ con- $_{477}$ tour is shown on both panels of Figure 2. The precip-478 itation $R_{\text {limit }}$ exceeds 0.5 over most of the equatoriah 79 oceans and the circulation $R_{\text {limit }}$ exceed 0.5 throughout480 the tropics. This indicates that the $S / N$ of GloSea5-481 $\mathrm{GC} 2$ is high enough to permit precipitation and circu-482 lation correlation skill greater than 0.5 over much of the483 tropics.

\subsection{Anomaly correlations}

To assess the global forecast skill, in Figure 3 we show ${ }^{488}$ the grid point anomaly correlations of GPCP JJA precipitation and the ERA-Interim vertical wind shear with their GloSea5-GC2 ensemble mean equivalents. In both fields, significant skill $(0.44, p<0.05)$ is restricted to the tropics, consistent with other state-of-the-art seasonal forecasting systems (Kim et al, 2012). Precipitation prediction skill is lower than circulation prediction skill. In both circulation and precipitation, the lowest skill in the tropics is located in the Indian Ocean, suggesting difficulties in seasonal prediction of the South Asian monsoon system. In the next section we examine the prediction skill of Indian monsoon precipitation and the South Asian monsoon circulation in detail.

\section{Indian summer monsoon forecast skill}

JJA AIR is a commonly used measure of seasonal monsoon rainfall (e.g. Rajeevan et al, 2012; Nanjundiah et al, 2013) and is reported in seasonal forecasts issued by the Indian Meteorological Department ${ }^{1}$. The interannual variation of AIR does not necessarily reflect the regional detail of the interannual variation of Indian rainfall (e.g. Ihara et al, 2007), but AIR is convenient for conducting a first-order assessment of monsoon seasonal prediction skill. JJA AIR anomalies in GPCP and GloSea5-GC2 are shown in Figure 4. The box plots represent the minimum, median, maximum and interquartile range of the ensemble, while the diamond represents the ensemble mean. In some years, such as 2008, the forecast is very good, with tight ensemble spread. In other years, such as 1997, all of the ensemble members predict the incorrect sign of the precipitation anomaly. Overall, the ensemble spread is large compared to the size of the anomalies, consistent with the $S / N$ map in Figure 2a. It is rare that all ensemble members predict anomalies of the same sign.

JJA anomalies of the Webster-Yang dynamical index, an index representing the strength of the largescale monsoon circulation using the vertical zonal wind shear over a large domain (difference between $850 \mathrm{hPa}$ and $200 \mathrm{hPa}$ over $40^{\circ}$ to $110^{\circ} \mathrm{E}, 0^{\circ}$ to $20^{\circ} \mathrm{N}$; Webster and Yang, 1992), are also shown in Figure 4. There is not a one-to-one relationship between correctly predicting Indian precipitation anomalies and correctly predicting the large scale circulation anomalies. In some years, such as 1997, the circulation anomaly is well predicted while the precipitation anomaly is poorly predicted. In other years, such as 1996, the precipitation is well predicted and the circulation is poorly predicted. In GloSea5-GC2, the monsoon circulation and precipitation over India are strongly related, with the ensemble mean correlating at $0.67(p<0.01)$. However, in the observations, they are quite unrelated, with a correlation of $0.18(p>0.1)$. This indicates precipitation over India is too directly forced by the large scale circulation

1 http://www.imd.gov.in/pages/monsoon_main.php 


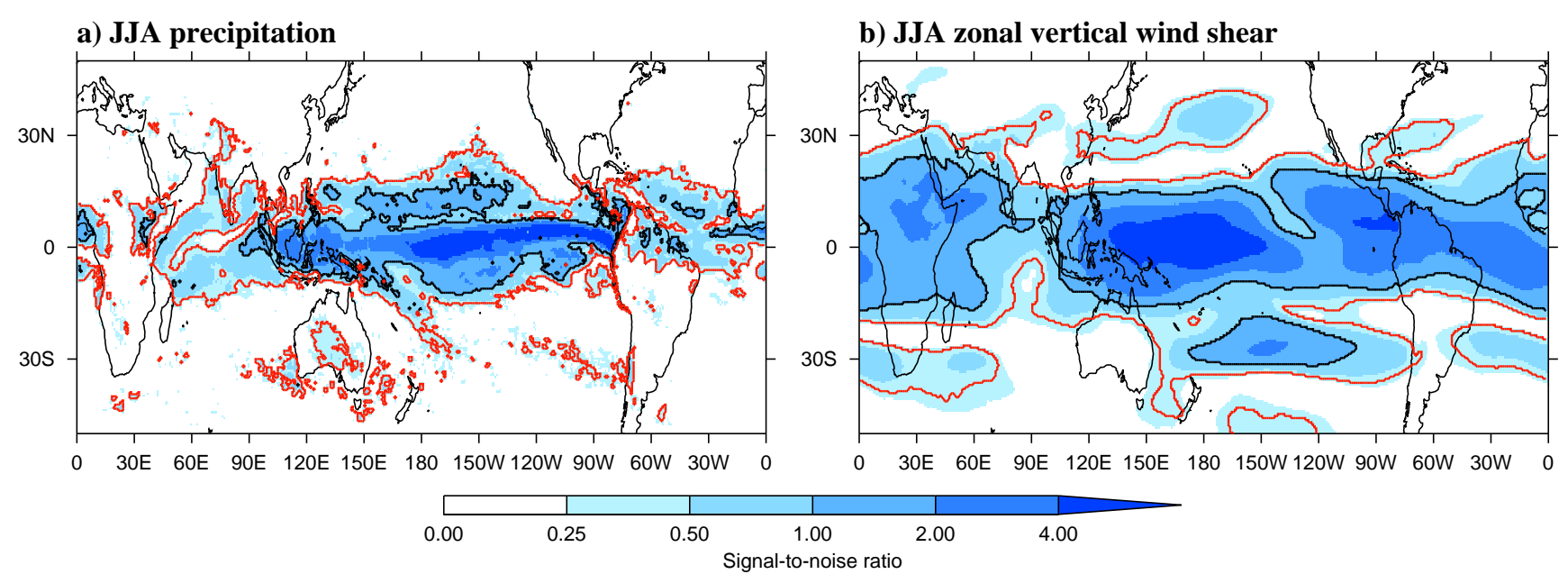

Fig. 2 Maps of GloSea5-GC2 JJA signal-to-noise ratio (see Section 3.2) for (a) precipitation and (b) zonal vertical wind shear $(850 \mathrm{hPa}-200 \mathrm{hPa})$. A signal-to-noise ratio greater than one is indicated by the dark solid contour. A theoretical correlation limit $\left(R_{\text {limit }}\right)$ of 0.5 is indicated by the red contour.

a) JJA precipitation

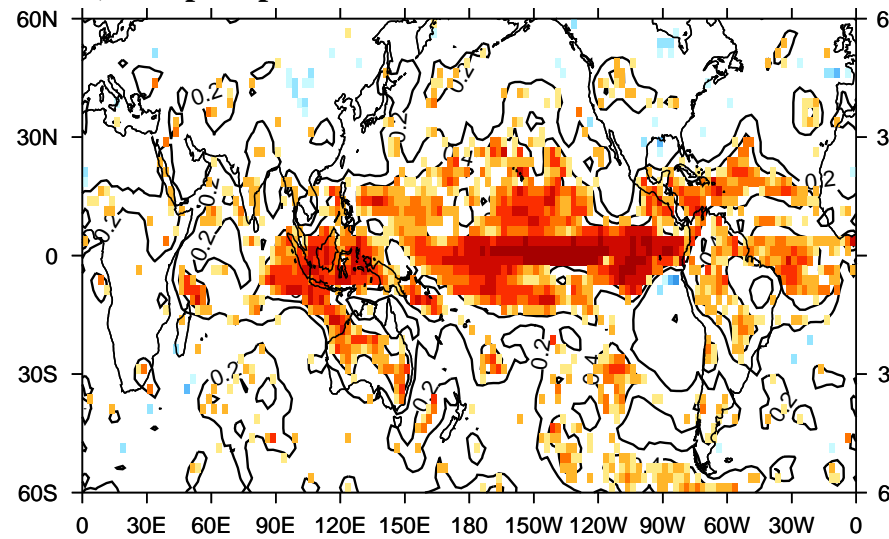

b) JJA zonal vertical wind shear $(850 \mathrm{hPa}-200 \mathrm{hPa})$

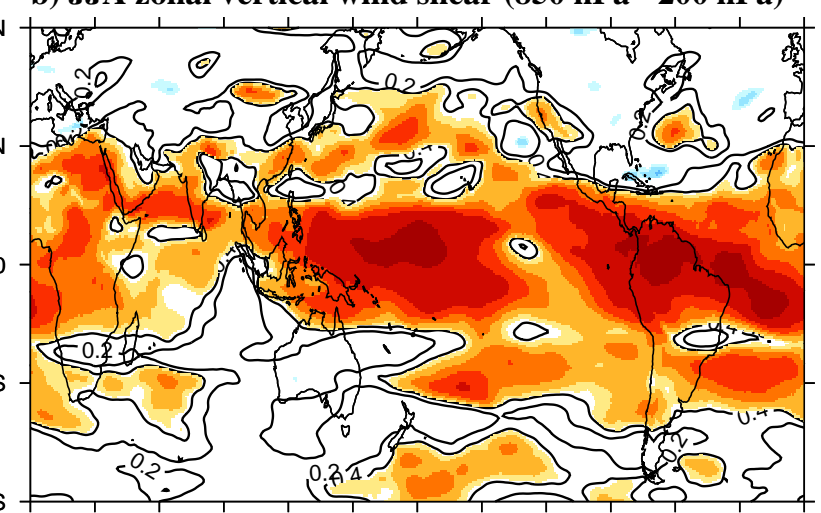

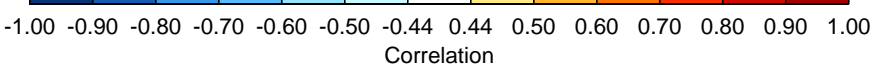

Fig. 3 Grid-point anomaly correlations of GPCP JJA precipitation and ERA-Interim JJA vertical wind shear with their GloSea5-GC2 ensemble mean equivalents. Significant skill $(0.44, p<0.05)$ is shaded, while lower skill is contoured at 0.2 and 0.4 .

in GloSea5-GC2. Ensemble spread in the Webster-Yang 507 index is still large compared to the magnitude of thesos mean anomaly, but less so than in JJA AIR, consistentrog with the $S / N$ maps in Figure 2.

A simple measure of forecast skill is the correlation $_{512}$ of observed and ensemble mean anomaly time series, such as those shown in Figure 4. We have listed these ${ }_{513}$ correlations in Table 1. The correlation of the $\mathrm{GPCP}_{514}$ and GloSea5-GC2 ensemble mean JJA AIR anomaly515 time series is $0.41(p<0.1)$. This indicates a mod-516 est level of skill, consistent with other forecast systems517 (Rajeevan et al, 2012). The Wang-Fan dynamical index518 represents the strength of the local Indian monsoon cir-519 culation in the northern Indian Ocean and over Indias2o itself using horizontal shear in the $850 \mathrm{hPa}$ zonal winds521 (difference between $40^{\circ}$ to $80^{\circ} \mathrm{E}, 5^{\circ}$ to $15^{\circ} \mathrm{N}$ and $70^{\circ}$ to $90^{\circ} \mathrm{E}, 20^{\circ}$ to $30^{\circ} \mathrm{N}$ Wang and Fan, 1999). The WangFan index shows a very similar correlation value $(0.36$, $p>0.1)$ to AIR, suggesting modest skill in predicting the local Indian monsoon circulation is related to the modest skill in predicting AIR.

The Webster-Yang dynamical index has a higher correlation of $0.66(p<0.01)$. This indicates that the large scale South Asian monsoon circulation is better predicted than the local Indian monsoon circulation and rainfall over India, consistent with the global correlation maps (Figure 3). However, this skill in predicting the Webster-Yang index is lower than that seen over a longer time period (1982-2009) with similar lead times and numbers of ensemble members in CfSv4 $(0.74, p<$ 

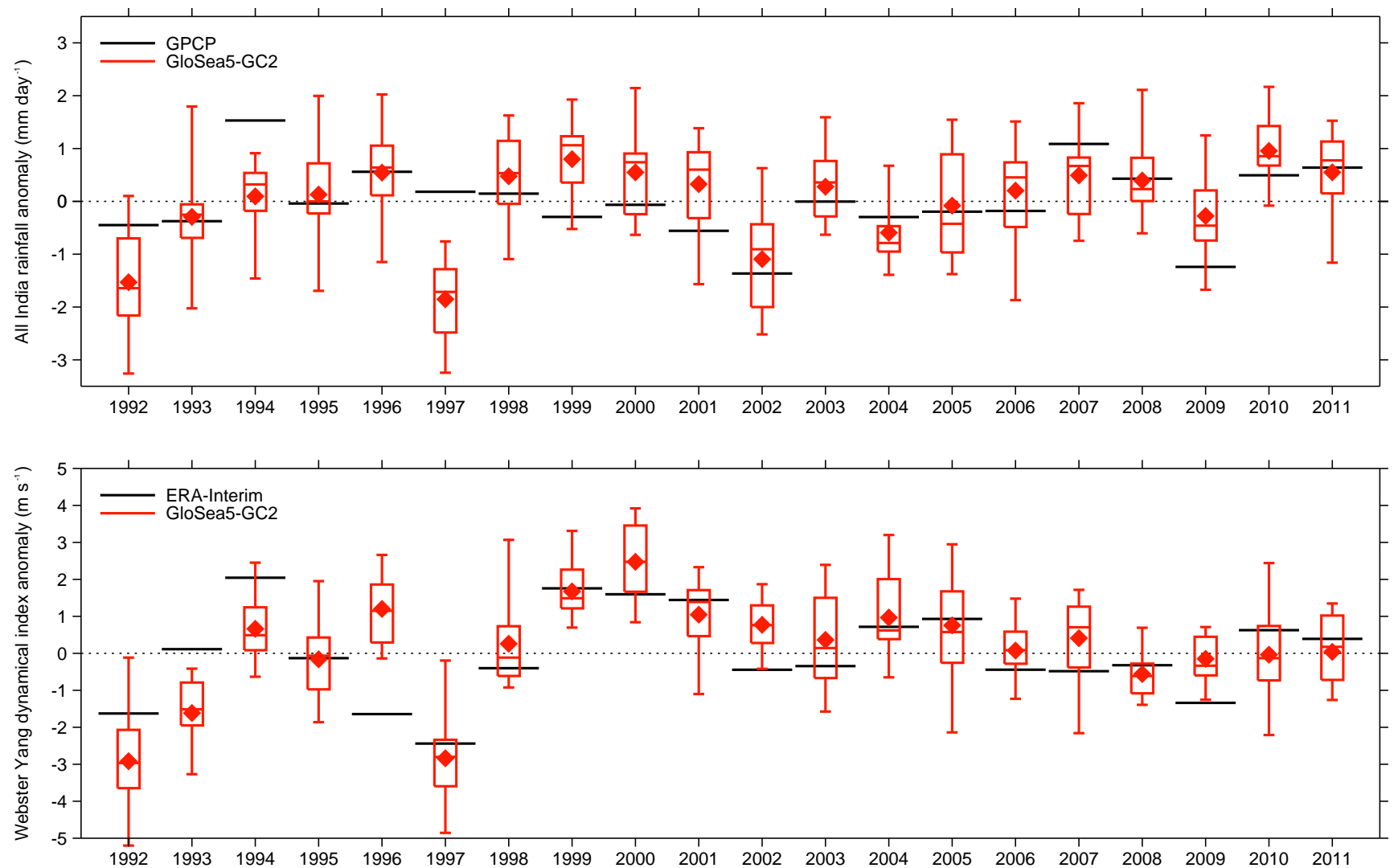

Fig. 4 JJA AIR (top) and Webster-Yang dynamical index (bottom) anomalies in GloSea5-GC2 (red), GPCP (top, black) and ERA-Interim (bottom, black). Box plots represent minimum, median, maximum and interquartile ranges of the ensemble, and the red diamond represents the ensemble mean. The Webster-Yang dynamical index subtracts the $850 \mathrm{hPa}$ winds from the 200 $\mathrm{hPa}$ winds over $40^{\circ}$ to $110^{\circ} \mathrm{E}$ and $0^{\circ}$ to $20^{\circ} \mathrm{N}$ (Webster and Yang, 1992).

Table 1 Evaluating the GloSea5-GC2 skill in representing JJA monsoon precipitation and circulation index anomalies (indices defined in the text). Column 1 lists the correlation of observed JJA anomalies with GloSea5-GC2 ensemble mean anomalies. Columns 2 and 3 compare the observed interannual standard deviation $(\sigma)$ to the hindcast sample median $\sigma$ in mm day ${ }^{-1}$ (see Figure 5).

\begin{tabular}{|l|c|c|c|}
\hline & $\begin{array}{c}\text { Correlation of } \\
\text { ensemble mean }\end{array}$ & $\begin{array}{c}\text { Observations } \\
\text { interannual } \sigma\end{array}$ & $\begin{array}{c}\text { Hindcast sample } \\
\text { median } \sigma\end{array}$ \\
\hline AIR & 0.41 & 0.69 & 1.06 \\
Wang-Fan index & 0.36 & 0.66 & 0.89 \\
Webster-Yang index & 0.66 & 1.21 & 1.62 \\
\hline
\end{tabular}

$0.01)$ and ECMWF System $4(0.78, p<0.01$, Kim et al,, 56 2012).

To evaluate the interannual variance, we calculate ${ }^{538}$ standard deviations $(\sigma)$ of the JJA time series of $\mathrm{AIR}_{540}^{539}$ Wang-Fan dynamical index and Webster-Yang dynamical index. Ensemble averaging enhances the component of interannual variability forced by slowly vary ${ }_{541}$ ing components of the climate system relative to at-542 mospheric noise, likely artificially lowering the interannual variance relative to observations. Accordingly, we 443 do not compare the ensemble mean $\sigma$ to the observa-544 tions. Instead we create distributions of $\sigma$ for each index 455 (Figure 5) using the hindcast samples described in Sec-546 tion 2.3.3 and compare the median to the observed $\sigma_{547}$ in Table 1. We find that in all indices, the variance in GloSea5-GC2 is too high, with the observed $\sigma$ well separated from the hindcast sample distribution. This is consistent with the high ensemble spread seen in Figures 2 and 4.

\section{Relationship between AIR and drivers of monsoon interannual variability}

Slowly evolving boundary conditions such as SST, snow and soil moisture provide sources of tropical rainfall seasonal prediction skill (Charney and Shukla, 1981). In this section, we assess the representation of relationships between AIR and slowly evolving boundary con- 


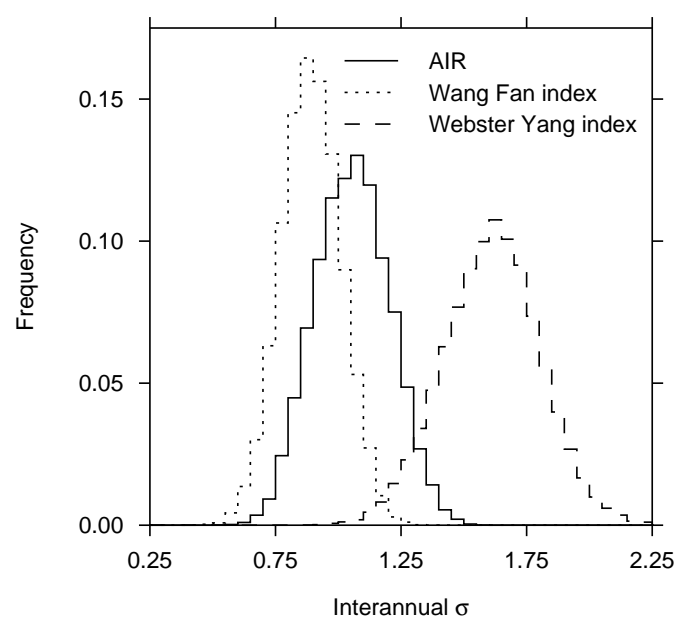

Fig. 5 Histograms of the standard deviation $(\sigma)$ of JJA anomalies of monsoon precipitation and circulation indices in the hindcast sample time series. Medians of these distributions are compared to observed $\sigma$ in Table 1 . The hindcast samples are described in Section 2.3.3. ditions in GloSea5-GC2. We perform a multiple linear regression analysis of AIR in observations and GloSea5GC2 using indices representing modes of variability such as ENSO and the IOD as independent variables. We use the regression coefficients as a diagnostic of the relationships and explore sources of error in relationships ${ }_{580}^{579}$ that are poorly represented. Correcting these errors has potential to improve forecast skill, making them impor- ${ }_{582}^{581}$ tant targets for model development.

\subsection{Indices}

We use five indices of slowly varying boundary condi-587 tions in our analysis. Four indices represent three modes ${ }^{588}$ of SST variability: ENSO, the IOD and the Atlantic ${ }^{589}$ Niño. The final index represents interannual variability ${ }^{500}$ in snow mass over the HimTP. Each index has published ${ }^{591}$ proposed physical mechanisms that link their interan ${ }^{-592}$ nual variability to interannual variability in AIR ( $\mathrm{se}^{593}$ review in Section 1). Table 2 defines the indices used.594 JJA anomalies are calculated relative to the time pe-595 riod covered by the hindcast set, 1992 to 2011, and are596

In Figure 6, regions used to calculate SST indices598 (Table 2) are overlaid on a JJA interannual correlations99 map of GloSea5-GO3 analysis SST and GloSea5-GC2500 ensemble mean SST. GloSea5-GC2 has much higheroo1 prediction skill for SST than it does for precipitation6o2 or the circulation (Figure 3). There are significant cor-603 relation values across the globe, but the highest valuesoo4 are in the tropics. We use the Niño-3.4 index to repre-605 sent the overall amplitude of ENSO and a trans-Niño0o6 index (TNI), calculated by subtracting the Niño-4 index607 not standardised.

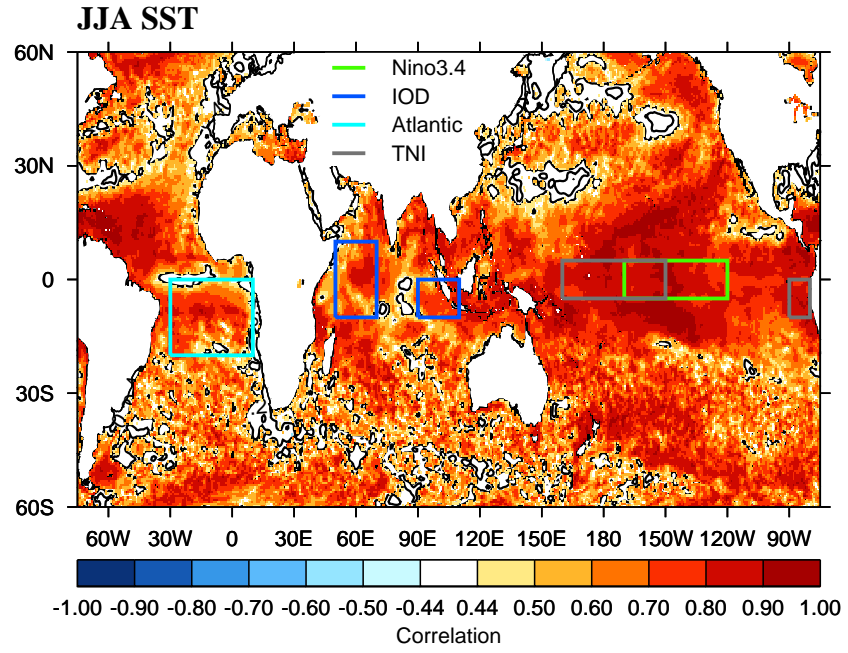

Fig. 6 Interannual correlation map of GloSea5-GO3 analysis and GloSea5-GC2 ensemble mean JJA SST. Grid points where the correlation is significant $(0.44, p>0.05)$ are shaded, while lower values are contoured. Most correlations are significant. The regions used as indices to represent modes of SST variability are outlined on this figure and listed in Table 2. Note that the Niño-4 region used to calculate the TNI index overlaps with the Niño-3.4 region from $120^{\circ} \mathrm{W}$ to $150^{\circ} \mathrm{W}$.

from the Niño-1.2 index, to represent the zonal position of the heating. TNI has a positive value in an east $\mathrm{Pa}$ cific El Niño, and a negative value in a central Pacific El Niño (Trenberth and Stepaniak, 2001). The IOD is represented by the IOD index (Saji et al, 1999), and the Atlantic Niño is represented by averaging SST anomalies over the region used in Kucharski et al (2007, 2008) (note this is the negative of the index used in Kucharski et al, 2007, 2008). The correlations of the GloSea5-GO3 analysis and the GloSea5-GC2 ensemble mean SST indices are is listed in Table 2. All four correlation values are high and significant $(p<0.01)$ and the ENSO indices (Niño-3.4 and the TNI) have the highest values. The GloSea5-GC2 skill in predicting these indices should generate AIR prediction skill if the mechanism linking them is well represented.

Following Turner and Slingo (2011), who showed that snow cover over HimTP is the most relevant to AIR interannual variability, we adopt their HimTP index (Table 2). Figure 7 shows this region, as well as the JJA climatological snow mass over the HimTP in GloSea5-GC2 (Figure 7a), the JJA bias against ERAInterim/Land (Figure 7b) and the JJA interannual correlation map with ERA-Interim/Land (Figure 7c). In ERA-Interim/Land, not much snow is present in JJA; the climatological HimTP JJA snow depth is only 2.56 $\mathrm{cm}$ of snow water equivalent (SWE). However, GloSea5GC2 is missing $37 \%$ of the ERA-Interim/Land snow mass; a bias of $-0.96 \mathrm{~cm}$ SWE. The correlation map 
Table 2 Definition of JJA indices used as independent variables in the regression analysis, including the quantity and averaging domain. Also listed are the interannual standard deviations $(\sigma)$ of the JJA indices in GloSea5-GO3 analysis and ERAInterim/Land, and the interannual correlation of the indices with the GloSea5-GC2 ensemble mean indices.

\begin{tabular}{|l|c|c|c|c|}
\hline Index & Quantity & Domain & Reanalysis $\sigma$ & Correlation \\
\hline Niño-3.4 & SST & $120^{\circ}-170^{\circ} \mathrm{W}, 5^{\circ} \mathrm{S}-5^{\circ} \mathrm{N}$ & $0.68\left({ }^{\circ} \mathrm{C}\right)$ & 0.87 \\
\hline IOD & SST & difference between & $0.49\left({ }^{\circ} \mathrm{C}\right)$ & 0.71 \\
& & $50^{\circ}-70^{\circ} \mathrm{E}, 10^{\circ} \mathrm{S}-10^{\circ} \mathrm{N}$ and & & \\
\hline ATL & $90^{\circ}-110^{\circ} \mathrm{E}, 10^{\circ} \mathrm{S}-0^{\circ}$ & & 0.79 \\
\hline TNI & SST & $30^{\circ} \mathrm{W}-10^{\circ} \mathrm{E}, 20^{\circ} \mathrm{S}-0^{\circ}$ & $0.40\left({ }^{\circ} \mathrm{C}\right)$ & 0.91 \\
& SST & difference between & $1.30\left({ }^{\circ} \mathrm{C}\right)$ & \\
& & $80^{\circ}-90^{\circ} \mathrm{W}, 10^{\circ} \mathrm{S}-0^{\circ}$ and & & 0.46 \\
\hline HimTP & Snow water equivalent (SWE) & $67.5^{\circ}-100^{\circ} \mathrm{E}, 27.5^{\circ}-40^{\circ} \mathrm{N}$ & $0.07(\mathrm{~cm} \mathrm{SWE})$ & $0.150^{\circ} \mathrm{S}, 5^{\circ} \mathrm{S}-5^{\circ} \mathrm{N}$ \\
\hline
\end{tabular}

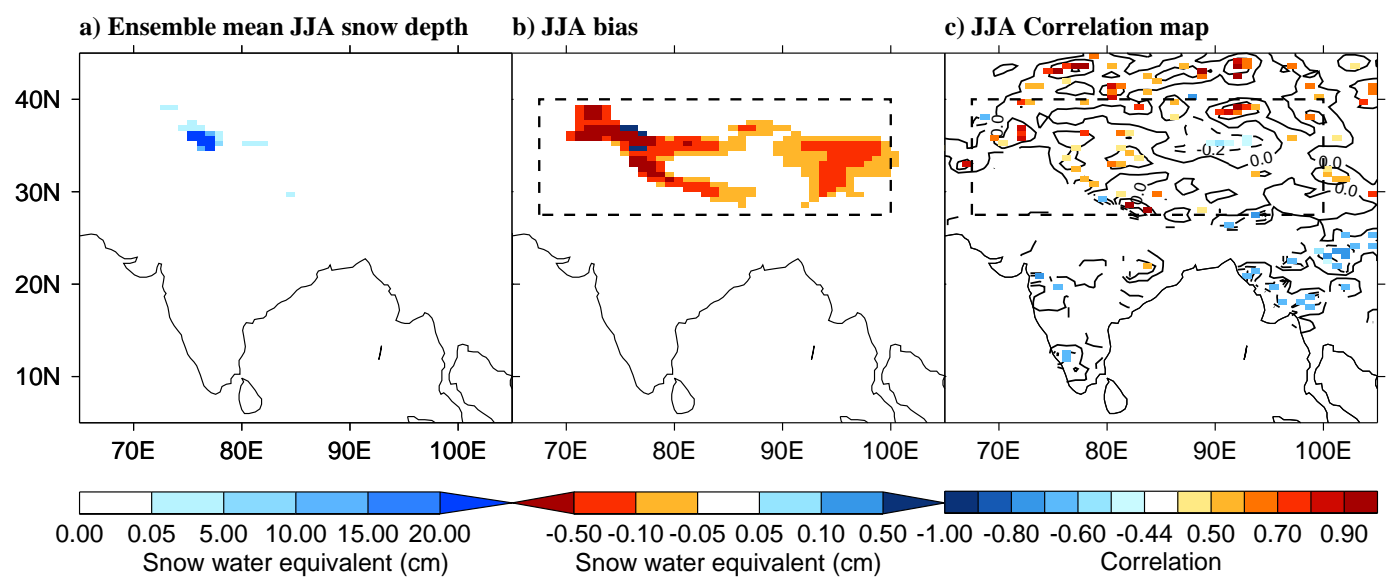

Fig. 7 a) Climatological JJA snow depth in GloSea5-GC2. b) JJA bias against ERA-Interim/Land. Also shown, as the dashed line, is the region used to calculate the HimTP index (Table 2). c) JJA interannual correlation map of ERA-Interim/Land and GloSea5-GC2 ensemble mean SWE. Grid points where the correlation is significant $(0.44, p>0.05)$ are shaded, while lower values are contoured at $0.0,0.2$ and 0.4 . Most correlations are in this domain insignificant.

shows that the interannual prediction skill of GloSea5-628 GC2 snow mass in the region is low, though it tends to629 be higher in the locations with the most snow. The in-6зо terannual correlation of the HimTP index is $0.46(p<631$ 0.05, Table 2), indicating modest skill. Consequently,632 even if the mechanism linking HimTP snow to AIR iso33 well represented in GloSea5-GC2, HimTP snow may634 contribute little to the overall prediction skill of AIR. ${ }_{635}$

To assess the relationship between AIR and the indices640 listed in Table 2, we perform a five parameter multiple 44 regression analysis with each index included as an inde-642 pendent variable. We first perform this analysis on the643 observed and ensemble mean indices. However, ensem-644 ble averaging enhances the component of interannual 45 variability forced by slowly varying boundary condi-646 tions relative to atmospheric noise, so comparing the647 relationships in the ensemble mean to the relationships648 in observations is unfair. To make a fair comparison ${ }_{549}$ we perform our regression analysis on the many indi-650 vidual 20 year JJA series selected from our ensemble members, as described in Section 2.3.3. We use the regression coefficients for each index, the standard error for each coefficient (a measure of uncertainty in the regression coefficient), and the final $R^{2}$ value for the fit in our analysis (see Section 2.3.1 for a detailed description of each of these statistics). Performing the regression analysis on the hindcast samples creates a distribution of each statistic, which illustrates the ensemble spread, to compare to the single value from the observations. The median of each distribution is listed in Table 3 with the statistics from the observed and ensemble mean regressions. We also show the hindcast sample distributions for the regression coefficients and the $R^{2}$ value in Figure 8.

The ensemble mean $R^{2}$ (Table 3 ) is much higher than the observed $R^{2}$, demonstrating that ensemble averaging enhances the forced component of the variability relative to the noise. In the rest of our analysis, we only compare the statistics from the hindcast samples to the observations. The hindcast sample median $R^{2}$ is lower than that of the observations, indicating there could be predictability from these indices that is 
unexploited in the GloSea5-GC2 system. However, theroo observed $R^{2}$ value falls well within the $R^{2}$ distribution ${ }_{71}$ in Figure 8, suggesting the $R^{2}$ values of the observa-702 tions and GloSea5-GC2 are consistent within the en-703 semble spread in GloSea5-GC2. We will now examinero4 the regression coefficient from each index in turn, asto5 a diagnostic of the relationship between AIR and thation index.

\subsubsection{ENSO}

As expected, the observations show a negative regres ${ }^{711}$ sion between Niño-3.4 and AIR in Figure 8, indicating ${ }^{712}$ that a positive Niño-3.4 anomaly, i.e. El Niño condi- ${ }^{713}$ tions, reduces AIR. The GloSea5-GC2 hindcast sample ${ }^{714}$ peak matches the observed value well, indicating the ${ }^{715}$ relationship between AIR and Niño-3.4 is well repre--716 sented. Regression maps of SST and precipitation on to ${ }^{717}$ the Niño-3.4 index confirm that the ENSO teleconnec ${ }^{-718}$ tions in observations and GloSea5-GC2 hindcasts are ${ }^{719}$ spatially very similar (not shown). This is likely the ${ }^{220}$ main source of the prediction skill in the Webster-Yang ${ }^{721}$ large-scale dynamical index (Figure 4).

The observations show a weak negative relationshipr23 between TNI and AIR, suggesting that an East $\mathrm{Pa}-724$ cific El Niño decreases AIR more than a central Pa-725 cific El Niño, which disagrees with Krishna Kumar et alz26 (2006). However, the regression is weak, with a $1 \sigma$ vari-727 ation in TNI resulting in a reduction in AIR of 0.14728 $\mathrm{mm}$ day $^{-1}$ (using Tables 2 and 3). There are also onlyz29 three El Niño years in our hindcast set (JJA Niño-3.4 $4_{30}$ anomaly $>0.5^{\circ} \mathrm{C}$ ), and one of them is the very largers1 east Pacific El Niño event of 1997, which likely domi-732 nates the relationship. Consequently, it is not surprising ${ }_{73}$ that the relationship between TNI and AIR is weak over ${ }_{34}$ this time period. The hindcast set replicates this weak ${ }_{35}$ relationship, with the peak of the distribution aligning ${ }_{736}$ with the observed value. This analysis indicates that ${ }_{37}$ the relationship between ENSO and AIR is well repre-738 sented in GloSea5-GC2.

\subsubsection{Indian Ocean dipole}

As expected, the observations show a large positive re-743 gression between the IOD index and AIR, indicating a $\mathrm{a}_{74}$ positive IOD increases AIR. The hindcast samples alsor45 show a positive regression, but at a much smaller value,746 and the value derived from observations falls in the ex-747 treme tail of the hindcast sample distribution. This sug-748 gests the relationship between the IOD and AIR is toor49 weak in GloSea5-GC2.

To confirm this interpretation and diagnose any re-751 lated errors in GloSea5-GC2, we calculate a multiple 52 regression with the same independent variables at each grid point in JJA maps of SST, land precipitation and $850 \mathrm{hPa}$ zonal and meridional winds. In Figure 9, the IOD index regression coefficient is shown for the observations, analogous to the dashed line on the IOD panel of Figure 8, and for the hindcast sample median, analogous to the median of the distribution in the IOD panel of Figure 8. In the observations, the expected IOD SST anomalies are clear, with warm anomalies in the WEIO and cool anomalies in the EEIO, especially off the coast of Sumatra and Java (Saji et al, 1999; Webster et al, 1999). The SST anomalies are associated with wind anomalies, including a strengthening of equatorial easterly winds and strengthening of the westerlies across the Arabian Sea, India and Indochina. This brings increased moisture transport to India, increasing monsoon precipitation (Ashok et al, 2001). In GloSea5$\mathrm{GC} 2$, the EEIO anomalies are too cold and extend to $70^{\circ} \mathrm{E}$, too far west. The WEIO SST anomalies are not warm enough, reducing the anomalous zonal SST gradient. The circulation anomalies and Indian precipitation anomaly are also weak.

Using wind stress correction experiments in HiGEM, an older version of the coupled MetUM (Shaffrey et al, 2009), Marathayil (2013) demonstrated that similar errors in IOD SST anomalies were due to a coupled mean state bias in the Indian Ocean. Stronger than observed mean state easterlies in the EEIO, which are related to errors in convective precipitation in the WEIO, lead to cooler than observed EEIO SSTs and increased upwelling, shoaling the thermocline in the east. The erroneously cool EEIO SSTs and erroneously warm WEIO SSTs reinforce the erroneously strong easterlies. This is consistent with the GloSea5-GC2 precipitation, SST and winds biases shown in Figure 1. We show the ensemble mean IO vertical temperature profile averaged from $3^{\circ} \mathrm{S}$ to $3^{\circ} \mathrm{N}$ in GloSea5-GC2 compared to EN4 analysis in Figure 10. The $20^{\circ} \mathrm{C}$ isotherm is highlighted as a proxy for thermocline depth. The thermocline is slightly too deep in the WEIO, and much too shallow in the EEIO in GloSea5-GC2, also consistent with the HiGEM bias (Marathayil, 2013).

This coupled mean state bias results in errors in the representation of the IOD. The shallower thermocline makes the EEIO SSTs more susceptible to wind anomalies during IOD initiation, leading to erroneously cool SST anomalies. The erroneous SST anomalies cause errors in the anomalous circulation and Indian precipitation, which could be further exacerbated by known errors in the representation of convective precipitation over the WEIO and India (Figure 1 and e.g. Bush et al, 2015). Marathayil (2013) demonstrated that mean state wind stress corrections in the EIO decrease these mean 


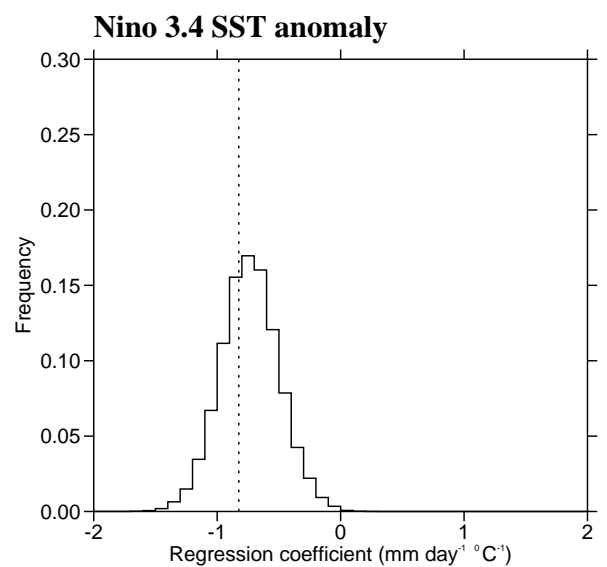

Indian Ocean dipole index

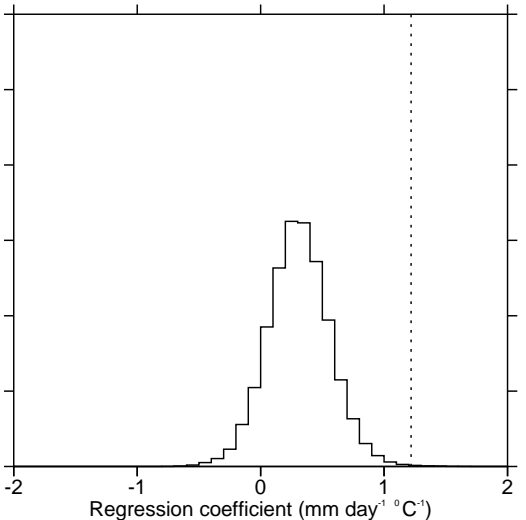

HimTP snow anomaly

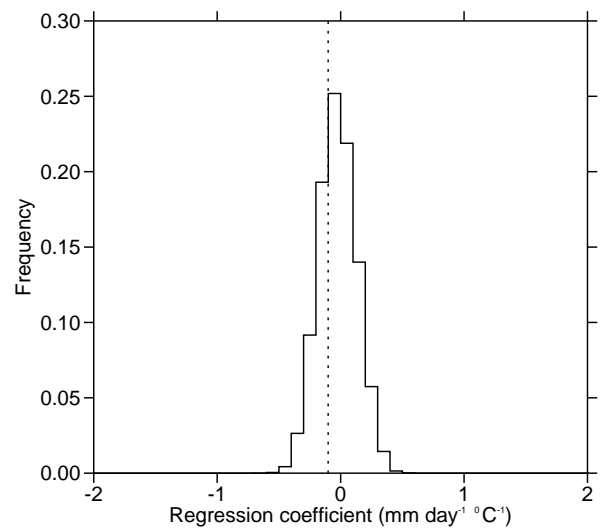

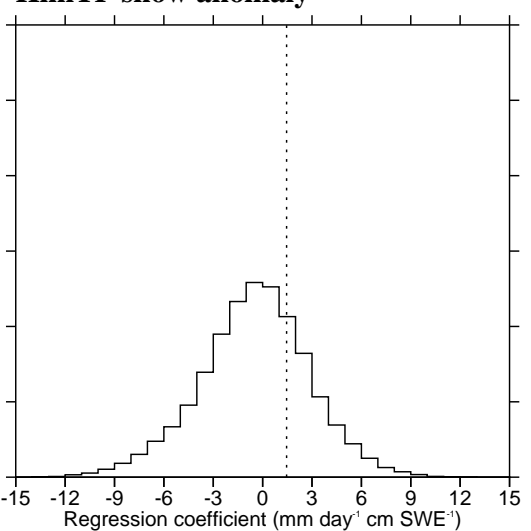

Tropical Atlantic SST anomaly

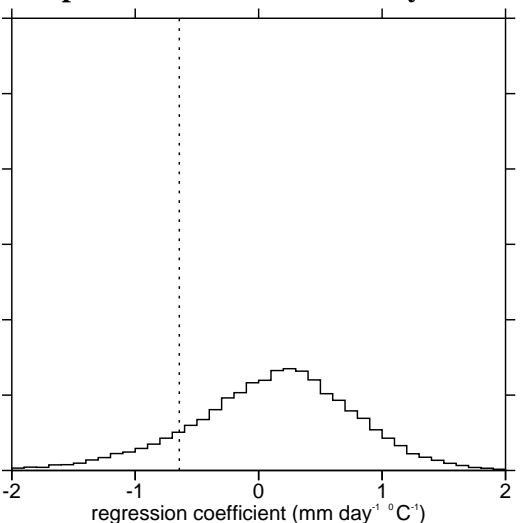

$\mathbf{R}^{2}$

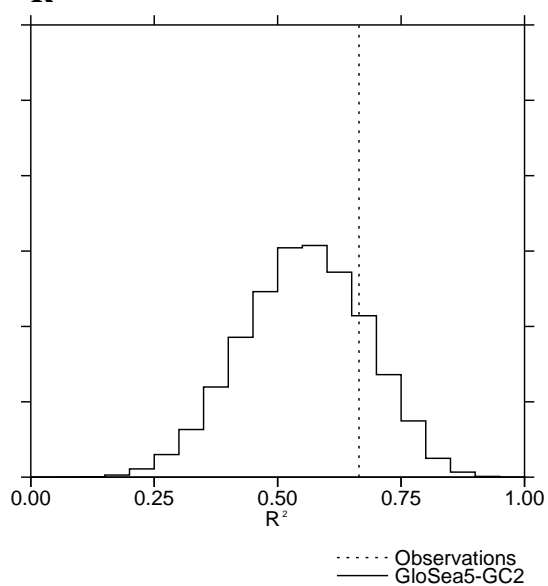

Fig. 8 Regression coefficients and $R^{2}$ from the five parameter JJA AIR multiple regression analysis. The dashed lines are the regression coefficients from observations, and the distributions in the solid lines show the results from many JJA series selected from the ensemble members in the GloSea5-GC2 hindcast set (Section 2.3.3).

a) Observations/analysis

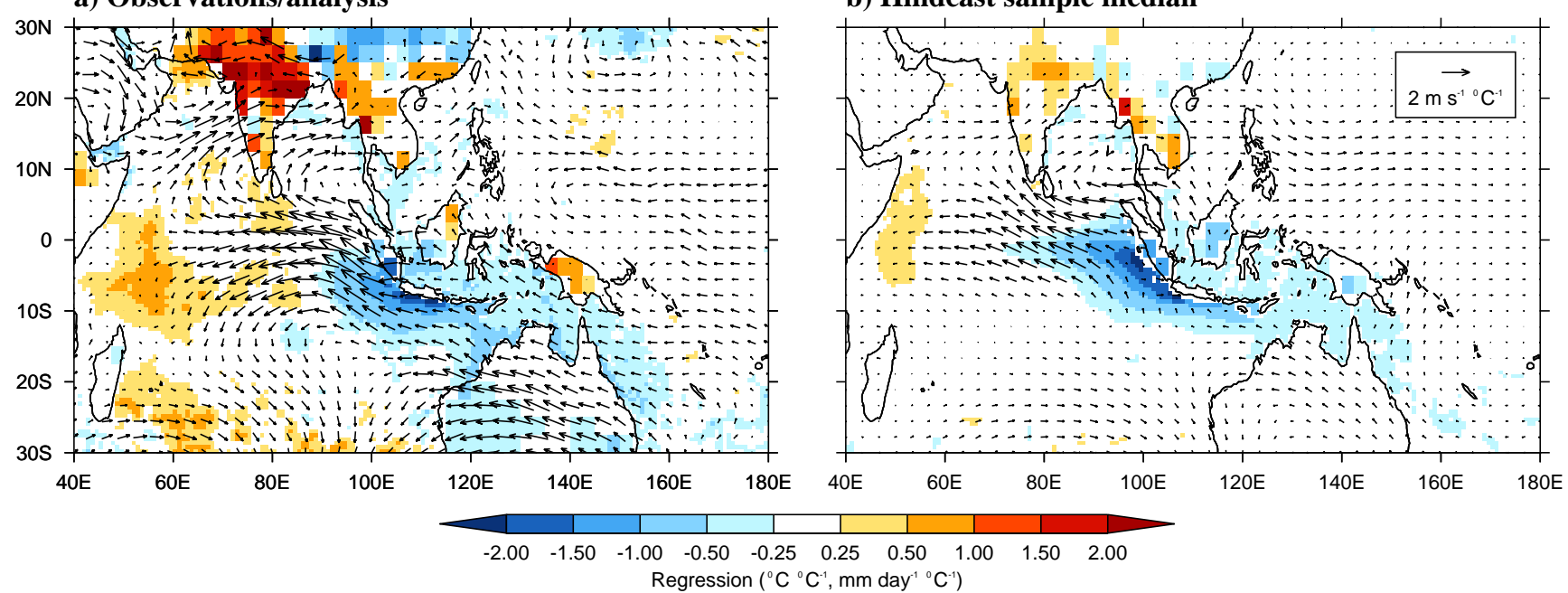

Fig. 9 Maps of the IOD regression coefficient from the five parameter regression analysis computed at each grid point of JJA SST, land precipitation and $850 \mathrm{hPa}$ winds in (a) GloSea5-GO3 analysis, GPCP and ERA-Interim and (b) GloSea5-GC2. For GloSea5-GC2, the regression is calculated for each hindcast sample and the median is taken at each grid point. The map in (a) is equivalent to the dotted line in the IOD panel of Figure 8 at each grid point and the map in (b) is equivalent to the median of the distribution in the IOD panel of Figure 8 at each grid point. 
Table 3 The regression coefficient and standard error for each independent variable in the multiple regression analysis of JJA indices with JJA AIR. The $R^{2}$ value for the regression is also listed. The statistics from the multiple regression analysis of the observations, statistics from the multiple regression analysis of the ensemble mean and the median of the hindcast sample statistics (median regression coefficient and median standard error) are all shown. The final line shows only the HimTP regression coefficient and standard error from a multiple regression analysis of June indices with June AIR. The units of regression coefficients and standard errors for SST indices are mm day ${ }^{-1}{ }^{\circ} \mathrm{C}-1$. The units of regression coefficients and standard errors for the HimTP snow indices are $\mathrm{mm}_{\text {day }}{ }^{-1} \mathrm{~cm} \mathrm{SWE}^{-1}$.

\begin{tabular}{|c|c|c|c|}
\hline & Obs and Analysis & Ensemble mean & Ensemble median \\
\hline Niño-3.4 & $-0.82 \pm 0.21$ & $-0.68 \pm 0.13$ & $-0.74 \pm 0.24$ \\
IOD & $1.22 \pm 0.26$ & $0.31 \pm 0.18$ & $0.31 \pm 0.28$ \\
Atlantic & $-0.64 \pm 0.33$ & $0.41 \pm 0.38$ & $0.15 \pm 0.61$ \\
TNI & $-0.10 \pm 0.09$ & $-0.02 \pm 0.08$ & $-0.03 \pm 0.16$ \\
HimTP Snow $^{2}$ & $1.45 \pm 1.62$ & $-1.06 \pm 2.13$ & $-0.35 \pm 3.15$ \\
R $^{2}$ & 0.66 & 0.79 & 0.56 \\
June HimTP Snow & $-1.54 \pm 1.21$ & $-2.14 \pm 2.63$ & $-2.18 \pm 4.70$ \\
\hline
\end{tabular}

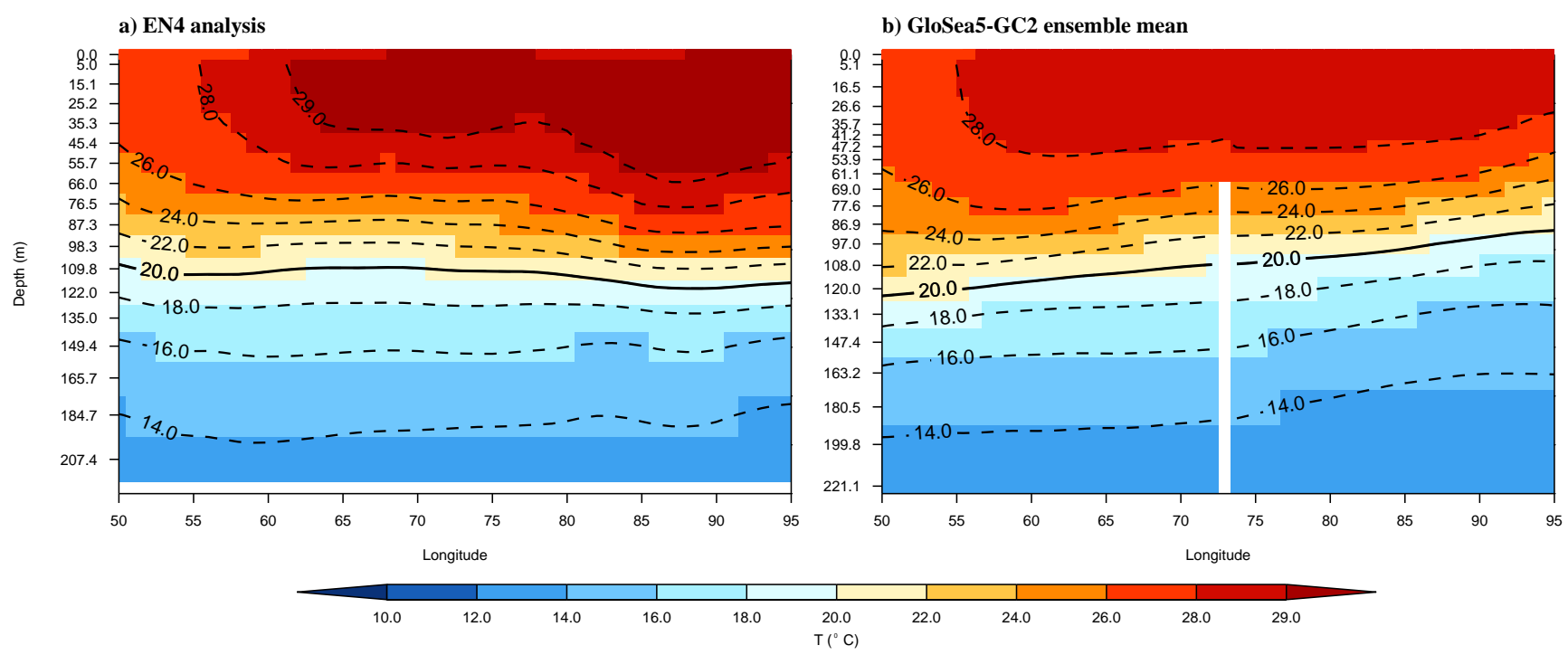

Fig. 10 Vertical profiles of Indian Ocean temperature at the equator, averaged from $3^{\circ} \mathrm{N}$ to $3^{\circ} \mathrm{S}$, in (a) GloSea5-GO3 SST analysis and EN4 subsurface analysis and (b) the GloSea5-GC2 ensemble mean. Each dataset is plotted on a similar set of its own levels which are listed on the y-axis. The solid line marks the $20^{\circ} \mathrm{C}$ isotherm, a proxy for thermocline depth. The white gap in the GloSea5-GC2 hindcast data is due to missing data at the location of the Andaman Islands.

state biases and result in a better representation of ther69 IOD SST anomalies in HiGEM. Improving this cou-770 pled mean state bias would likely improve AIR predic-771 tion skill and prediction skill in the Indian Ocean basin 72 more broadly.

\subsubsection{Atlantic Niño}

As suggested by Kucharski et al (2007, 2008), the ob-777 servations show a negative regression between the At-778 lantic index and AIR, indicating warm tropical Atlantic79 SSTs decrease AIR or, conversely, that cool tropical At-780 lantic SSTs increase AIR. However, the hindcast sam-781 ples show a wide distribution created by the ensemble 82 spread in GloSea5-GC2, that peaks at a slightly positivers value and has tails extending to $\pm 2 \mathrm{~mm}$ day ${ }^{-1}{ }^{\circ} \mathrm{C}^{-1} .784$ While the Niño-3.4 and IOD regression coefficients inz85 GloSea5-GC2 have similar standard errors to the stan-786 dard errors derived from observations (Table 3), the Atlantic index regression coefficient has nearly double the standard error in the hindcast samples than in the observations, indicating that the regression values are not as constrained in GloSea5-GC2 as they are in the observations. These results motivate a more detailed analysis of the representation of the mechanism linking Atlantic SST anomalies to AIR in GloSea5-GC2.

Kucharski et al $(2007,2008)$ use an ensemble of atmospheric GCM integrations, coupled only in the Indian Ocean, to compare experiments forced by interannually varying Atlantic SSTs with control integrations forced by climatological Atlantic SSTs. Their experiments show an equatorial Rossby wave response to Atlantic Niño anomalies which creates a quadrupole structure in upper level eddy stream function and modifies the low level circulation in the Indian Ocean (Kucharski et al, 2007, Figure 6). Cool anomalies create anomalous 


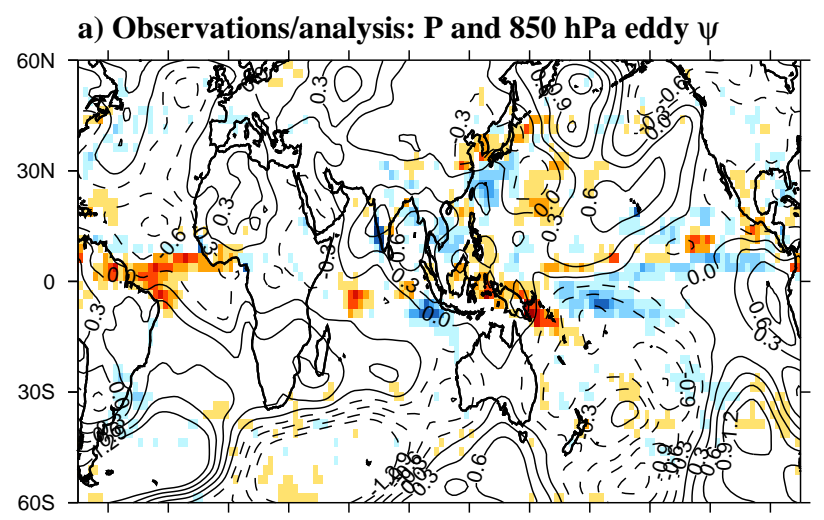

\section{b) GloSea5-GC2: P and 850 hPa eddy $\psi$}

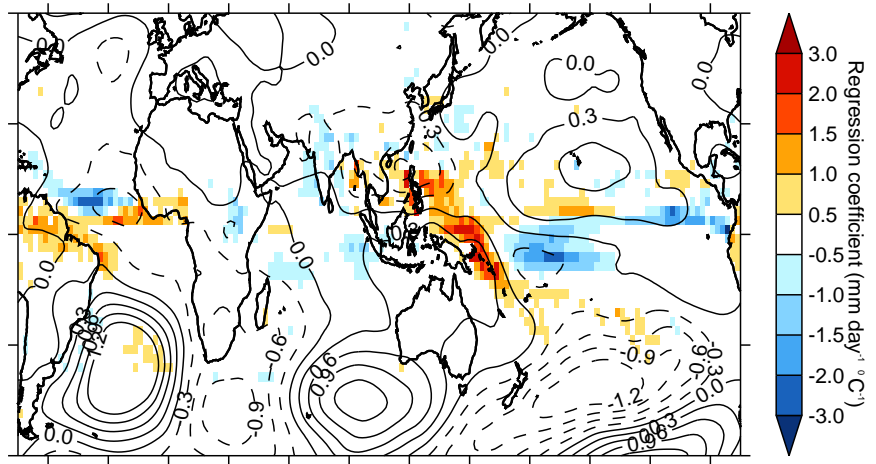

d) $200 \mathrm{hPa} \chi$ and eddy $\psi$

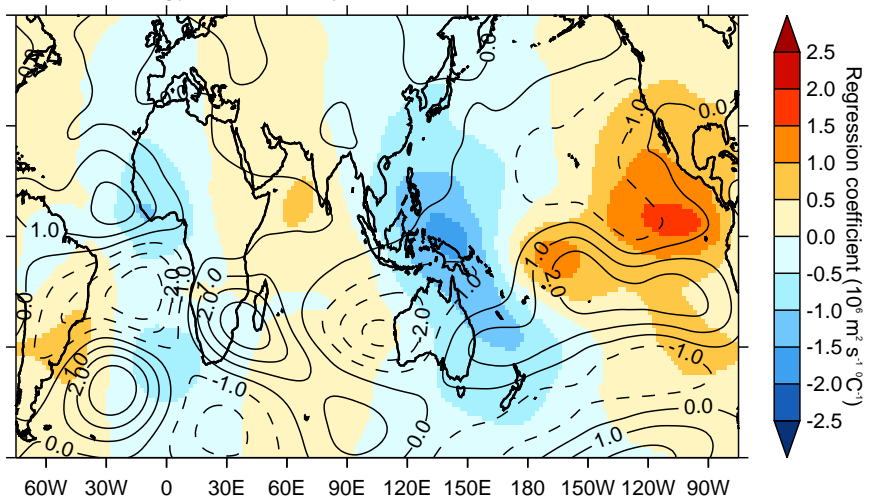

60W 30W 0 30E 60E 90E 120E 150E 180 150W 120W 90W

60W 30W 0 30E 60E 90E 120E 150E 180 150W 120W 90W

Fig. 11 Maps of regression coefficients of precipitation (shading, a and b), $850 \mathrm{hPa}$ eddy stream function (contours, a and b), $200 \mathrm{hPa}$ eddy stream function (contours, c and d) and velocity potential (shading, c and d) regressed against the Atlantic index in GPCP, ERA-interim and the GloSea5-GC2 hindcast samples that are within 0.05 of the observed Atlantic regression value in Figure 8. First, each grid point of each of these fields was regressed against the Niño-3.4 index. Then the residual was regressed against the Atlantic Niño index, creating the regression coefficients shown here. $850 \mathrm{hPa}$ stream function contours are spaced by $0.310^{6} \mathrm{~m}^{2} \mathrm{~s}^{-1}{ }^{\circ} \mathrm{C}^{-1}$ and $200 \mathrm{hPa}$ stream function contours are spaced by $10^{6} \mathrm{~m}^{2} \mathrm{~s}^{-1}{ }^{\circ} \mathrm{C}^{-1}$.

low level cyclones in the equatorial Indian Ocean on ei-8os ther side of the equator which increase moisture con-810 vergence and precipitation over India (Kucharski et al,811 2008, Figure 3).

To determine whether this mechanism is acting in $^{813}$ GloSea5-GC2, we regressed maps of the precipitation, ${ }^{814}$ 850 and $200 \mathrm{hPa}$ eddy stream function, and $200 \mathrm{hPa} \mathrm{ve}^{-815}$ locity potential against the Atlantic index. The Kucharsk16 et al $(2007,2008)$ study included the effects of ENSO in ${ }^{817}$ both the experiments and the control, so the effects of ${ }^{18}$ ENSO should be excluded from their results. To anal- ${ }^{819}$ yse as similar a diagnostic as possible, we first regress ${ }^{820}$ the GloSea5-GC2 fields against the Niño-3.4 index and $d^{821}$ then regress the residual against the Atlantic index. $\mathrm{To}^{822}$ clarify the response, we calculate the regression maps ${ }^{823}$ individually for 768 of the $3 \times 10^{4}$ GloSea5-GC2 hind- ${ }^{824}$ cast samples which have Atlantic regression coefficients ${ }^{825}$ between -0.59 and -0.69 (within 0.05 of the observed ${ }^{226}$ value, Figure 8). We averaged the sample regression ${ }^{827}$ maps to create the final maps shown in Figure 11. We $\mathrm{We}^{828}$ also show the equivalent regression maps derived from ${ }^{829}$ GPCP and ERA-Interim.
As the hindcast samples were selected based on the proximity of their rainfall regression value to the observed regression value, it is not surprising that negative rainfall anomalies over India are associated with positive Atlantic SST anomalies in both GPCP and the GloSea5-GC2 samples in Figure 11. However, the smooth response of the velocity potential and the quadrupole structure in upper level stream function shown in Kucharski et al (2007) are not present in the GloSea5-GC2 hindcast samples or ERA-Interim. The low level Indian Ocean cyclones shown in Kucharski et al (2008), which would correspond to the low level anti-cyclones in Figure 11, are also missing in GloSea5-GC2. Instead, anomalous upper level divergence is seen broadly over the Atlantic and west Pacific, and upper level convergence is seen in the east Pacific and Indian Ocean, though the magnitude and pattern differ considerably between ERAInterim and the GloSea5-GC2 samples. There is a low level anti-cyclone present over India in ERA-Interim, but it is not mirrored south of the equator. There is no clear wave-like pattern that is consistent between ERA-Interim and GloSea5-GC2 in upper or lower level 
stream function. Similar maps made using all $3 \times 10^{4}{ }_{822}$ hindcast samples give similar results (not shown). $\quad{ }_{883}$

Pottapinjara et al (2014) introduced another diag-884 nostic of the influence of tropical Atlantic SSTs on thes85 Indian monsoon. Using NCEP reanalysis (Kanamitsubs6 et al, 2002) and the HadISST sst dataset (Rayner et al,887 2003), they correlate Atlantic SST indices with globals8 tropospheric temperature anomaly $\left(1000 \mathrm{hPa}\right.$ to $200_{889}$ $\mathrm{hPa}$ ) maps after the influence of ENSO has been re-890 moved from both. This reveals a Gill-type (Gill, 1980) g91 $_{91}$ tropospheric temperature heating response to warm SS F98 $_{9}$ in the tropical Atlantic that extends into the tropi-893 cal Indian Ocean (Pottapinjara et al, 2014, Figure 10).894 They argue that the tropospheric temperature increaseg95 in the Indian Ocean reduces the meridional temper-996 ature gradient that drives the South Asian monsoon,897 reducing Indian rainfall. This is consistent with thes98 Kucharski et al $(2007,2008)$ results showing cool trop-899 ical Atlantic SSTs increase Indian rainfall.

We reproduce this Pottapinjara et al (2014) diagnos-901 tic in ERA-Interim reanalysis and the 768 GloSea5-GC2902 hindcast samples that agree with the observed Atlantic-903 AIR regression coefficient and show it in Figure 12.904 In ERA-Interim, tropospheric temperature warming is correlated with the Atlantic index over the tropical Atlantic and Indian Ocean. However it does not extend ${ }^{005}$ as far into the Indian Ocean, or correlate as strongly ${ }^{906}$ with the Atlantic index as shown in Pottapinjara et al ${ }^{907}$ (2014). In GloSea5-GC2 the correlation over the trop- ${ }^{908}$ ical Atlantic is weaker and it does not extend to the ${ }^{009}$ Indian Ocean. The Atlantic index used in this study is ${ }^{910}$ different than the Atlantic index used in Pottapinjara $a^{911}$ et al (2014), but repeating the analysis with their At1 $3^{912}$ index does not change the results.

We conclude that the wave mechanisms described in Kucharski et al $(2007,2008)$ are not acting in GloSea5$\mathrm{GC} 2$, even in the hindcast samples with a similar re- ${ }_{915}$ gression coefficient to the coefficient derived from ob- ${ }_{916}$ servations. That ERA-Interim also does not show the mechanisms prompts questions about the validity and ${ }^{917}$ robustness of these mechanisms. Kucharski et al (2007, 2008) study 1950 to 1999 and Pottapinjara et al (2014) ${ }_{920}^{919}$ study 1979 to 2012, so it is possible that decadal vari- ${ }_{921}$ ability has altered or obscured this mechanism in the 1992 to 2011 time period we analyse here. Further study ${ }_{923}$ of the Atlantic Niño-AIR teleconnection and its varia- ${ }_{923}$ tion over time is needed to unify these results.

\subsubsection{Him TP snow}

Turner and Slingo (2011) and Senan et al (2015) show,929 using experiments that initialise anomalous snow опэз April 1, that increased HimTP snow cover reduces sur-931 face sensible and long wave heating as proposed by Blanford (1884), which delays the onset of the monsoon and significantly reduces monsoon rainfall in June. In these experiments, snow anomalies persist from April through June. The snow anomalies' impact on June monsoon rainfall combines two effects: the effect previous, spring snow cover had on the tropospheric temperature gradient that initiated the monsoon and the effect current, June snow cover has on current surface temperatures and radiative balances. In order to consider ensemble members from all initialisation dates in the GloSea5-GC2 hindcast set as one ensemble, we must analyse the impact of snow anomalies at a time sufficiently removed from the hindcast initialisation dates. Consequently, we do not consider snow before June in this analysis. This means we only analyse the relationship between summer snow cover anomalies and monsoon rainfall anomalies. For consistency with our JJA analysis, we initially examine the relationship between JJA snow anomalies and JJA rainfall anomalies, but later in this section we examine the relationship between June snow anomalies and June rainfall anomalies, where we would expect to see a larger impact.

In the observations, HimTP snow shows a positive regression with AIR in JJA. This is the opposite of the expected relationship via the Blanford mechanism (Blanford, 1884). A $1 \sigma$ variation in JJA HimTP snow cover results in an increase of $0.1 \mathrm{~mm} \mathrm{day}^{-1}$ in JJA rainfall (using Tables 2 and 3), indicating almost no relationship between JJA HimTP snow and JJA AIR. The hindcast samples are consistent with this lack of relationship.

However, Turner and Slingo (2011) showed that the main impact of HimTP snow on AIR is in June, and its relationship with June precipitation may not be strong enough to be detectable in JJA precipitation. To test the representation of the relationship in June, we repeated the entire multiple regression analysis with June indices and, in Figure 13 and Table 3, we show the HimTP snow regression coefficients. The June regression derived from observations is indeed negative, but roughly the same magnitude as the JJA regression. June snow in ERA-Interim/Land has a higher interannual standard deviation, $0.21 \mathrm{~cm}$ SWE, than JJA snow, so $1 \sigma$ variation in June snow leads to a slightly larger impact on June rainfall, $0.3 \mathrm{~mm}$ day ${ }^{-1}$. The hindcast samples have a broad distribution, peaking at the observed value, suggesting GloSea5-GC2 is correctly representing this small negative impact current snow cover has on June Indian rainfall. 


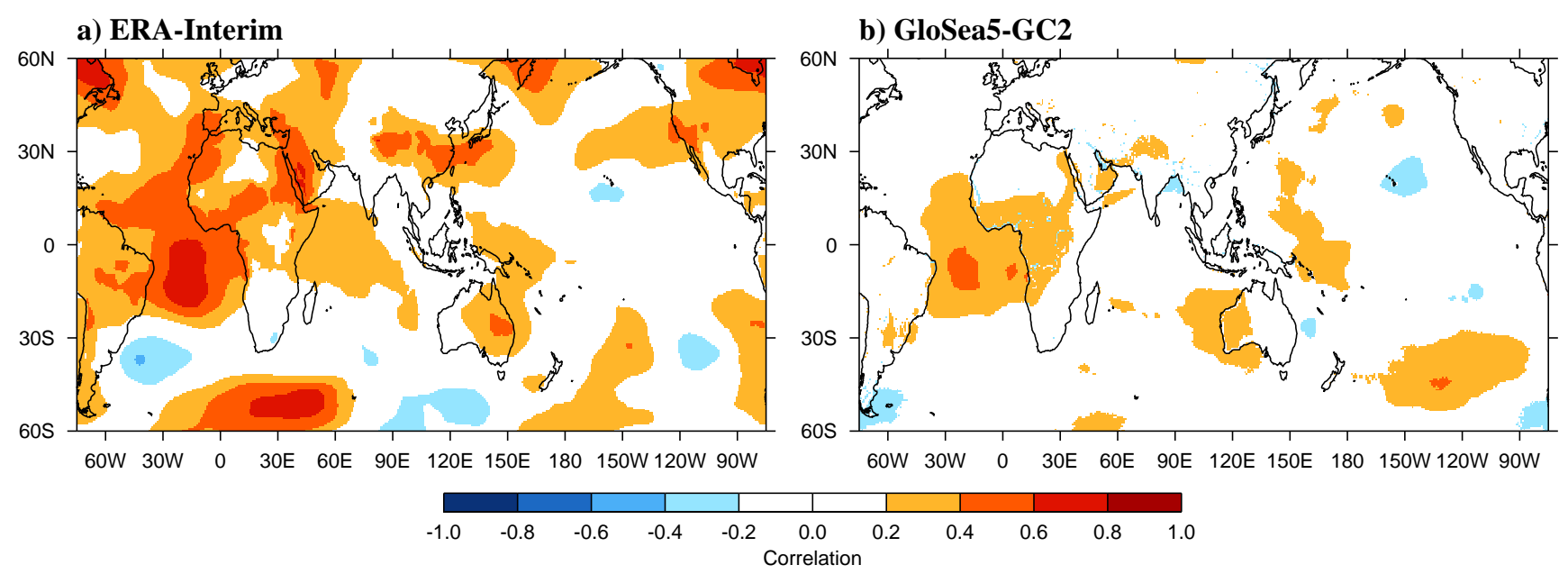

Fig. 12 Correlation of the JJA tropospheric temperature anomaly (averaged from 1000 to $200 \mathrm{hPa}$ ) with the JJA Atlantic SST index, after a regression against Niño-3.4 has been removed from each. a) ERA-Interim. b) Average correlation of the GloSea5-GC2 hindcast samples that are within 0.05 of the observed Atlantic regression value in Figure 8.

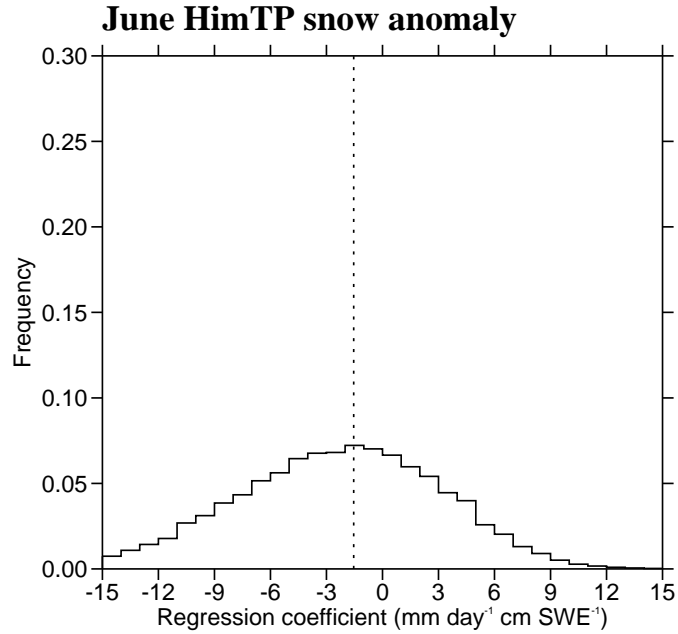

Fig. 13 HimTP snow index regression coefficients in the five parameter June multiple regression analysis. The dashed line ${ }^{958}$ is the observed value, and the distribution in the solid line $e^{959}$ shows the results from many June series selected from the960 ensemble members in the GloSea5-GC2 hindcast set. (1)

To assess the importance of each of these indices to967 this regression, we use forward selection (Section 2.3.2).968 In this technique, indices are each regressed separatelyo69 against AIR. The index with the highest $R^{2}$ value iss7o then regressed against AIR in combination with each of 71 the remaining indices in turn. The process is repeatedor2 until all of the indices are included as independent vari-973 ables in the regression. The ordering of the indices andor4 the increase in $R^{2}$ as each index is added, reflect the 75 importance of the index in explaining the interannuab76 variability of AIR.
In both the observations and GloSea5-GC2, the Niño3.4 and IOD indices are most important in explaining the interannual variability in AIR over the hindcast period. Their combined $R^{2}$ values are 0.53 and 0.46 in the observations and hindcast samples, respectively, compared to $R^{2}$ value when all five indices are included of 0.66 and 0.56 (listed in Tables 3 and 4). The remaining three indices add similar, smaller contributions to the $R^{2}$ in observations and GloSea5-GC2. This means it is difficult to separate them in order of importance, and we consequently focus on the differences in $R^{2}$ for the Niño-3.4 index and the IOD index.

In Table 4, we summerise the results of the forward selection for the Niño-3.4 and IOD indices. In the observations, the IOD index explains most of the variance in AIR, with a single $R^{2}$ of 0.27 , while in GloSea5-GC2, Niño-3.4 explains most of the variance with a single $R^{2}$ of 0.39 . The two indices are similarly correlated with each other in the GloSea5-GO3 analysis (0.33) and the GloSea5-GC2 ensemble mean (0.28), indicating the relationship between ENSO and the IOD is consistent between the observations and GloSea5-GC2. The combined results from the forward selection and multiple regression analysis suggest that the weakness of the relationship between AIR and the IOD causes AIR to respond too consistently to ENSO anomalies in GloSea5GC2, as seen in other forecast systems (Kim et al, 2012), and consequently Niño-3.4 explains too much of the variance in AIR in GloSea5-GC2 and the IOD index explains too little. If the relationship between AIR and the IOD were correctly represented, it would at times reinforce the AIR anomaly forced by ENSO, and at times counteract that anomaly, leading to a weaker overall correlation between ENSO and AIR and less 
Table 4 Summary of results from forward selection. $R^{2}$ foro18 a single regression of Niño-3.4 or the IOD index against $\mathrm{AIR}_{1019}$ is shown in the first two rows, the $R^{2}$ for the combined regression of both indices against AIR is shown in the third ${ }^{1020}$ row.

\begin{tabular}{|c|c|c|}
\hline & $\begin{array}{c}\text { Observations and } \\
\text { Analysis }\end{array}$ & $\begin{array}{c}\text { Hindcast sample } \\
\text { median }\end{array}$ \\
\hline Niño-3.4 & 0.10 & 0.39 \\
\hline IOD & 0.27 & 0.02 \\
\hline Niño-3.4 \& IOD & 0.53 & 0.46 \\
\hline
\end{tabular}

interannual variability explained by ENSO, consistent ${ }_{028}$ with the observations.

\section{Discussion and Conclusions}

We have assessed the seasonal prediction skill of sum To34 mer all-India rainfall (AIR) and the representation of fo35 $_{35}$ mechanisms contributing to predictability of AIR in the $e_{036}$ GloSea5-GC2 coupled ensemble seasonal forecast sys $_{\mathrm{r}_{\mathrm{T} 37}}$ tem. GloSea5-GC2 has notable mean state biases, $\mathrm{in}_{\text {I0з3 }}$ cluding equatorial SST cold biases in all basins. The Indian Ocean has the lowest JJA precipitation and cir $_{\mathrm{ro40}}$ culation signal-to-noise ratios and prediction skill in the $\mathrm{q}_{041}$ tropics, consistent with other state-of-the-art seasonałb42 forecast systems (Rajeevan et al, 2012).

GloSea5-GC2 has moderate skill in predicting $\mathrm{JJA}^{1043}$ AIR $(0.41, p<0.1)$. However, it has much higher skil1 ${ }^{104}$ in predicting the large scale circulation $\left(0.66\right.$ for the $e^{1045}$ Webster-Yang dynamical index, $p<0.01)$, consistent ${ }^{1046}$ with other forecast systems. ENSO, the most widespread mode of interannual SST variability, and the relation ${ }^{1048}$ ship between ENSO and AIR are well represented in ${ }^{1049}$ GloSea5-GC2. This indicates that the AIR interannual ${ }^{1050}$ variability related to the large-scale circulation in GloSeas5$\mathrm{GC} 2$ is well represented. However, the basin-scale rela- ${ }^{1052}$ tionship between AIR and the IOD is weak in GloSea5 $5^{1053}$ GC2. Our analysis showed this likely due to a coupled ${ }^{\text {t054 }}$ mean state bias in the Indian Ocean which alters the $e^{1055}$ amount of anomalous SST cooling/warming that re- ${ }^{1056}$ sults from anomalous wind forcing, giving erroneous ${ }^{1057}$ IOD SST anomalies. Known difficulties in represent- ${ }^{1058}$ ing convective precipitation over India may also play alo5s role (e.g. Bush et al, 2015). Due to the lack of respons@oro to the IOD, AIR responds more consistently to ENSQ 061 in GloSea5-GC2 than in observations, which manifest\$o62 itself in an erroneously high correlation between ENSQ $_{063}$ indices and AIR.

Our analysis did not show a teleconnection from the065 tropical Atlantic Niño region to the Indian subcontito66 nent in GloSea5-GC2. However, when analysed over theobr time period available from the GloSea5-GC2 hindcastoos set, this teleconnection was not clear in ERA-Interimmog either. This suggests further work is needed to confirm the validity and establish the robustness of the Kucharski et al $(2007,2008)$ mechanism connecting the the Atlantic Niño region to AIR. Our analysis also indicated the response of June Indian rainfall to June HimTP snow anomalies in GloSea5-GC2 agrees with observations, but is small in both.

Due to the relatively few years in our hindcast set, we analysed all years in our hindcast set together, rather than studying years with an especially strong anomaly in a given index, such as ENSO events. In twenty years there are only a few events of any type, so analysis of strong anomaly years would be very dependent on the GloSea5-GC2 performance in a few individual years. However, A limitation of our analysis is that our general conclusions may not apply to an individual year. For example, we cannot conclude from our analysis that the 1997 forecast bust is necessarily due to a misrepresentation of the IOD-AIR relationship rather than a misrepresentation of the ENSO-AIR relationship. We can conclude that the IOD-AIR relationship is generally misrepresented in GloSea5-GC2, and improving it will improve forecast skill over the hindcast period as a whole, independent of whether it improves forecast skill in a specific year such as 1997.

In agreement with our analysis, recent assessments of seasonal forecast skill have generally found that ENSO anomalies and the response of AIR to the ENSO anomalies are well represented in GCMs (Kim et al, 2012; Rajeevan et al, 2012; Nanjundiah et al, 2013). The representation of the relationship between AIR and the IOD is increasingly recognised as a source of error. Consistent with our analysis of the coupled Indian Ocean SST/wind bias, Rajeevan et al (2012) showed in the ENSEMBLES and DEMETER samples of coupled seasonal forecast systems that air-sea coupling in the Indian Ocean basin is too strong. Nanjundiah et al (2013) studied five coupled seasonal forecast systems from the ENSEMBLES sample and found that the relationship between AIR and the equatorial Indian Ocean zonal wind anomalies is generally poorly represented.

In GloSea5-GC2, the application of mean state bias correction techniques to reduce the error in circulation and equatorial SSTs in the Indian Ocean may improve both the representation of IOD anomalies, as Marathayil (2013) showed for the coupled GCM HiGEM, and the relationship between the IOD and AIR. As the IOD is the major mode of interannual variability in the Indian Ocean, we expect that an improved representation of the Indian Ocean mean state and the IOD would have a significant impact on precipitation and circulation seasonal prediction skill in the Indian Ocean (Fig- 
ure 3), and would likely improve AIR prediction skill a\$121 well.

1122

Conditions in the equatorial Indian Ocean are im+123 portant for the correct initiation and propagation of the124 boreal summer intraseasonal oscillation (e.g. Sperber125 and Annamalai, 2008). The propagation and amplitude126 of the BSISO are weak in GloSea5-GC2 (Jayakumar127 et al, 2016). Given the similarity in pattern between128 the leading mode of interannual variability in monsoom²9 circulation and a component of the intraseasonal vari1130 ability, and that the frequency of occurrence of this in ${ }^{1131}$ traseasonal variability projects onto interannual varia ${ }_{132}$ tions (Sperber et al, 2000), poor simulation of Indian133 Ocean intraseasonal variability may also therefore im¹34 pact on the skill of interannual rainfall prediction. Fur"135 ther analysis should address the relationship between136 errors in the Indian Ocean mean state, the IOD and137 intraseasonal variability in seasonal forecast systems. ${ }^{1138}$

Acknowledgements SJJ would like to acknowledge Dr. Emannue Dutra for his help accessing and understanding ERA-Interim/14tand reanalysis data.

SJJ, AGT and SJW gratefully acknowledge the finan $\overline{\overline{1143}}_{3}$ cial support given by the Earth System Science Organization, Ministry of Earth Sciences, Government of India (Grant no. MM/SERP/Univ_Reading_UK/2013/INT13/002) to conduct $t^{145}$ this research under Monsoon Mission. SJW was supported by146 the National Centre for Atmospheric Sciences Climate direc $\overline{\overline{1}}_{147}$ torate, a Natural Environment Research Council collaboration under contract R8/H12/83/001. GMM was supported ${ }^{148}$ by the Joint UK DECC/Defra Met Office Hadley Centre Cli1149 mate Programme (GA01101).

\section{References}

Adler RF, Huffman GJ, Chang A, Ferraro R, Xie ${ }^{1155}$ PP, Janowiak J, Rudolf B, Schneider U, Curtis S, Bolvin D, Gruber A, Susskind J, Arkin P, Nelkin $\mathrm{E}^{157}$ (2003) The Version-2 Global Precipitation Climatol- ${ }^{158}$ ogy Project (GPCP) Monthly Precipitation Analysis ${ }^{1159}$ (1979 - Present). Journal of Climate 4:1147-1167

Annamalai H, Murtugudde R, Potemra J, Xie SP, Liu ${ }^{1161}$ P, Wang B (2003) Coupled dynamics over the Indian ${ }^{1162}$ Ocean: spring initiation of the Zonal Mode. Deep ${ }^{163}$ Sea Research II 50:2305-2330, DOI 10.1016/S0967- ${ }^{1164}$ 0645(03)00058-4

Ashok K, Guan Z, Yamagata T (2001) Impact of the Indian Ocean Dipole on the Relationship between ${ }^{1167}$ the Indian Monsoon Rainfall and ENSO. Geophys- ${ }^{1168}$ ical Research Letters 28(23):4499-4502

Balsamo G, Albergel C, Beljaars A, Boussetta S, Brun ${ }^{1170}$ E, Cloke H, Dee D, Dutra E, Munoz-Sabater J, Pap- ${ }^{171}$ penberger F, dr Rosnay $\mathrm{P}$, Stockdale $\mathrm{T}$, Vitart $\mathrm{F}^{1172}$ (2015) ERA-Interim/Land: a global land surface re- ${ }^{1173}$ analysis data set. Hydrology and Earth System Sciences 19:389-407, DOI 10.5194/hess-19-389-2015

Best MJ, Pryor M, Clark DB, Rooney GG, Essery RLH, Menard CB, Edwards JM, Hendry MA, Porson A, Gedney N, Mercado LM, Sitch S, Blyth E, Boucher O, Cox PM, Grimmond CSB, Harding RJ (2011) The Joint UK Land Environment Simulator (JULES), model description Part 1: Energy and water fluxes. Geoscientific Model Development 4:677699, DOI 10.5194/gmd-4-677-2011

Bevington (1969) Data Reduction and Error Analysis for the Physical Sciences, 1st edn. McGraw-Hill, New York

Blanford HF (1884) On the Connexion of the Himalaya Snowfall with Dry Winds and Seasons of Drought in India. Proceedings of the Royal Society of London 37:3-22

Blockley EW, Martin MJ, Mclaren AJ, Ryan AG, Waters J, Lea DJ, Mirouze I, Peterson KA, Sellar A, Storkey D (2014) Recent development of the Met Office operational ocean forecasting system: an overview and assessment of the new Global FOAM forecasts. Geoscientific Model Development 7:26132638, DOI 10.5194/gmd-7-2613-2014

Bowler NE, Arribas A, Beare SE, Mylne KR, Shutts GJ (2009) The local ETKF and SKEB: Upgrades to the MOGREPS short-range ensemble prediction system. Quarterly Journal of the Royal Meteorological Society 135:767-776, DOI 10.1002/qj

Bush SJ, Turner AG, Woolnough SJ, Martin M, Klingaman NP (2015) The effect of increased convective entrainment on Asian monsoon biases in the MetUM general circulation model. Quarterly Journal of the Royal Meteorological Society 141:311-326, DOI 10.1002/qj.2371

Chang P, Fang Y, Saravanan R, Ji L, Seidel H (2006) The cause of the fragile relationship between the $\mathrm{Pa}$ cific El Nino and the Atlantic Nino. Nature 443:324328, DOI 10.1038/nature05053

Charney JG, Shukla J (1981) Predictability of Monsoons, Cambridge University Press, chap 6, pp 99109

Cionni I, Eyring V, Lamarque JF, Randel WJ, Stevenson DS, Wu F, Bodeker GE, Shepherd TG, Shindell DT, Waugh DW (2011) Ozone database in support of CMIP5 simulations: results and corresponding radiative forcing. Atmospheric Chemistry and Physics 11:11,267-11,292, DOI 10.5194/acp-11-11267-2011

Dee DP, Uppala SM, Simmons AJ, Berrisford P, Poli P, Kobayashi S, Andrae U, Balmaseda MA, Balsamo G, Bauer P, Bechtold P, Beljaars ACM, Berg LVD, Bidlot J, Bormann N, Delsol C, Dragani R, Fuentes M, Geer AJ, Dee DP (2011) The ERA-Interim reanaly- 
sis: configuration and performance of the data assim+227 ilation system. Quarterly Journal of the Royal Mete 228 orological Society 137:553-597, DOI 10.1002/qj.8281229

Fasullo J (2004) A Stratified Diagnosis of the Indianezo Monsoon Eurasian Snow Cover Relationship. Jour $¥ 231$ nal of Climate 17:1110-1122

1232

Gill AE (1980) Some simple solutions for heat-induced $\mathrm{l}_{33}$ tropical circulation. Quarterly Journal of the Royallz34 Meteorological Society 106:447-462

1235

Goddard L, Mason SJ, Zebiak SE, Ropelewski $\mathrm{CF}_{1,236}$ Basher R, Cane MA (2001) Current approaches to237 seasonal-to-interannual climate predictions. Internat238 tional Journal of Climatology 21:1111-1152, DOI 1239 $10.1002 /$ joc. 636

1240

Good SA, Martin MJ, Rayner NA (2013) EN4: Qual ${ }_{+241}$ ity controlled ocean temperature and salinity profile\$2 42 and monthly objective analyses with uncertainty esł243 timates. Journal of Geophysical Research 118:6704 ${ }_{1244}$ 6716, DOI 10.1002/2013JC009067

1245

Gouretski V, Reseghetti F (2010) On depth and tem +246 perature biases in bathythermograph data: Developł247 ment of a new correction scheme based on analysi\$248 of a global ocean database. Deep-Sea Research Part249 I 57:812-833, DOI 10.1016/j.dsr.2010.03.011, URI http://dx.doi.org/10.1016/j.dsr.2010.03.011 1251

Ihara C, Kushnir Y, Cane A, Pena VHDL (2007) Indianes2 summer monsoon rainfall and its link with ENSO and $\mathrm{d}_{23}$ Indian Ocean climate indices. International Journal254 of Climatology 27:179-187, DOI 10.1002/joc 1255

Jayakumar A, Turner A, Johnson SJ, Rajagopal EN $\mathrm{N}_{1,256}$ Mohandas S, Mitra AK (2016) Boreal summer subt257 seasonal variability of the South Asian monsooness in the Met Office GloSea5-GC2 initialized coupled259 model. Climate Dynamics submitted

1260

Ju J, Slingo J (1995) The Asian summer monsoon and261 ENSO. Quarterly Journal of the Royal Meteorologit262 cal Society 121:1133-1168

1263

Kanamitsu M, Ebisuzaki W, Woollen J, Yang SK , 264 Hnilo JJ, Fiorino M, Potter G (2002) NCEPDOF 265 AMIP-II reanalysis (R-2). Bulletin of the Americane66 Meteorological Society (November):1631-1643, DOI ${ }_{1267}$ 10.1175/BAMS-83-11-1631

1268

Kang IS, Shukla J (2006) Dynamic seasonal predictione69 and predictability of the monsoon, Springer/Praxisiz70 Chichester, UK, chap 15, pp 585-612

Kim HM, Webster PJ, Curry JA, Toma VE (2012) $)_{272}$ Asian summer monsoon prediction in ECMWF Syst273 tem 4 and NCEP CFSv2 retrospective seasonałz74 forecasts. Climate Dynamics 39:2975-2991, DOI 1275 10.1007/s00382-012-1470-5

1276

Krishna Kumar K, Rajagopalan B, Hoerling M, Bate\$277 G, Cane M (2006) Unraveling the Mystery of Indianrz8 Monsoon Failure During El Nino. Science 314:115
119, DOI 10.1126/science.1131152

Krishnamurthy V, Shukla J (2000) Intraseasonal and Interannual Variability of Rainfall over India. Journal of Climate 13:4366-4377

Krishnamurthy V, Shukla J (2007) Intraseasonal and Seasonally Persisting Patterns of Indian Monsoon Rainfall. Journal of Climate 20:3-20, DOI 10.1175/JCLI3981.1

Kucharski F, Bracco A, Yoo JH, Moltini F (2007) LowFrequency Variability of the Indian Monsoon ENSO Relationship and the Tropical Atlantic: The Weakening of the 1980s and 1990s. Journal of Climate 20:4255-4266, DOI 10.1175/JCLI4254.1

Kucharski F, Bracco A, Yoo JH, Molteni F (2008) Atlantic forced component of the Indian monsoon interannual variability. Geophysical Research Letters 35:1-5, DOI 10.1029/2007GL033037

Levine RC, Turner AG (2012) Dependence of Indian monsoon rainfall on moisture fluxes across the Arabian Sea and the impact of coupled model sea surface temperature biases. Climate Dynamics 38:21672190, DOI 10.1007/s00382-011-1096-z

Levine RC, Turner AG, Marathayil D, Martin GM (2013) The role of northern Arabian Sea surface temperature biases in CMIP5 model simulations and future projections of Indian summer monsoon rainfall. Climate Dynamics 41:155-172, DOI 10.1007/s00382012-1656-x

Li G, Xie Sp (2012) Origins of tropical-wide SST biases in CMIP multi-model ensembles. Geophysical Research Letters 39:L22,703, DOI 10.1029/2012GL053777

Li G, Xie SP (2014) Tropical Biases in CMIP5 Multimodel Ensemble: The Excessive Equatorial Pacific Cold Tongue and Double ITCZ Problems. Journal of Climate 27:1765-1780, DOI 10.1175/JCLI-D-1300337.1

MacLachlan C, Arribas A, Peterson KA, Maidens A, Fereday D, Scaife AA, Gordon M, Vellinga M, Williams A, Comer RE, Camp J, Xavier P, Madec G (2015) Global Seasonal forecast system version 5 (GloSea5): a high-resolution seasonal forecast system. Quarterly Journal of the Royal Meteorological Society 141(689):1072-1084, DOI 10.1002/qj.2396

Marathayil D (2013) The Indian Ocean mean state and variability in a high resolution coupled climate model: HiGEM. PhD thesis, University of Reading Megann A, Storkey D, Aksenov Y, Alderson S, Calvert D, Graham T, Hyder P, Siddorn J, Sinha B (2014) GO5.0: the joint NERC Met Office NEMO global ocean model for use in coupled and forced applications. Geoscientific Model Development 7:1069-1092, DOI 10.5194/gmd-7-1069-2014 
Mogensen KS, Balmaseda MA, Weaver A, Martin $\mathrm{MJ}_{1333}$ Vidard A (2009) NEMOVAR: A variational data aSt334 similation system for the NEMO ocean model ${ }_{1335}$

Nanjundiah RS, Francis PA, Ved M, Gadgil S (2013)336 Predicting the extremes of Indian summer monsoon337 rainfall with coupled ocean atmosphere models. $\mathrm{Cur}^{+338}$ rent Science 104:1380-1393

1339

Palmer T, Anderson D (1994) The prospects for seat340 sonal forecasting - A review paper. Quarterly Journals41 of the Royal Meteorological Society 120(518):755-793342

Pottapinjara V, Girishkumar MS, Ravichandran $\mathrm{M}_{1,343}$ Murtugudde R (2014) Journal of Geophysical344 Research : Atmospheres. Journal of Geophysit345 cal Research: Atmospheres 119:6456-6469, DOI ${ }_{1346}$ 10.1002/2014JD021494.Received

1347

Rae JGL, Hewitt HT, Keen AB, Ridley JK, West AE 1,348 Harris CM, Hunke EC, Walters DN (2015) Developł349 ment of the Global Sea Ice 6.0 CICE configuration for350 the Met Office Global Coupled model. Geoscientific351 Model Development 8:2221-2230, DOI 10.5194/gmdra52 8-2221-2015

1353

Rajeevan M, Unnikrishnan CK, Preethi B (2012) Eval+554 uation of the ENSEMBLES multi-model seasonalk55 forecasts of Indian summer monsoon variability. $\mathrm{Cli}_{3+356}$ mate Dynamics 38:2257-2274, DOI 10.1007/s00382 r557 011-1061-x

1358

Rayner NA, Parker DE, Horton EB, Folland $\mathrm{CK}_{1,359}$ Alexander LV, Rowell DP, Kent EC, Kaplan A (2003)360 Global analyses of sea surface temperature, sea ice, 361 and night marine air temperature since the late nineł362 teenth century. Journal of Geophysical Research $108_{1,363}$ DOI 10.1029/2002JD002670

1364

Rowell DP, Folland CK, Maskell K, Ward MN (1995) 1365 Variability of summer rainfall over tropical northis66 Africa (1906-92): Observations and modelling. Quar+367 terly Journal of the Royal Meteorological Society368 121:669-704

1369

Saji NH, Goswami BN, Vinayachandran PN, Yamagatasтo $\mathrm{T}$ (1999) A dipole mode in the tropical Indian Ocean ${ }_{1371}$ Nature 401:360-363

1372

Senan R, Orsolini YJ, Weisheimer A, Vitart F, Balsamøв73 G, Stockdale T, Dutra E, Doblas-Reyes FJ, Basang374 D (2015) Impact of springtime Himalayan-Tibetank75 Plateau snowpack on the onset of the Indian sum+376 mer monsoon in coupled seasonal forecasts. Climate377 Dynamics under revision pp 1-41

1378

Shaffrey LC, Stevens I, Norton WA, Roberts MJ, Vitz79 dale PL, Harle JD, Jrrar A, Stevens DP, Woodag@s8 MJ, Demory ME, Donners J, Clark DB, Clayton $A_{1,381}$ Cole JW, Wilson SS, Connelley WM, Davies $\mathrm{TM}_{1,382}$ Iwi AM, Johns TC, King JC, New AL, Slingo JM-,383 Slingo A, Steenman-Clark L, Martin GM (2009) U.K.1384 HiGEM: The New U. K. High-Resolution Globad385
Environment Model - Model Description and Basic Evaluation. Journal of Climate 22:1861-1896, DOI 10.1175/2008JCLI2508.1

Shukla J, Paolino DA (1983) The Southern Oscillation and Long-Range Forecasting of the Summer Monsoon Rainfall over India. Monthly Weather Review 111:1830-1837

Sperber KR, Annamalai H (2008) Coupled model simulations of boreal summer intraseasonal (30-50 day) variability, Part 1: Systematic errors and caution on use of metrics. Climate Dynamics 31(23):345-372, DOI 10.1007/s00382-008-0367-9, URL http://www.springerlink.com/index/10.1007/s00382008-0367-9

Sperber KR, Slingo J, Annamalai H (2000) Predictability and the relationship between subseasonal and interannual variability. Quarterly Journal of the Royal Meteorological Society 126:2545-2574

Sperber KR, Annamalai H, Kang IS, Kitoh A, Moise A, Turner AG, Wang B, Zhou T (2013) The Asian summer monsoon: an intercomparison of CMIP5 vs. CMIP3 simulations of the late 20th century. Climate Dynamics 41:2711-2744, DOI 10.1007/s00382012-1607-6

Trenberth KE, Stepaniak DP (2001) Indices of El Nino Evolution. Journal of Climate 14:1697-1701

Turner AG, Slingo J (2011) Using idealized snow forcing to test teleconnections with the Indian summer monsoon in the Hadley Centre GCM. Climate Dynamics 36(9-10):17171735, DOI $10.1007 / \mathrm{s} 00382-010-0805-3$, URL http://www.springerlink.com/index/10.1007/s00382010-0805-3

Valcke S (2013) The OASIS3 coupler: a European climate modelling community software. Geoscientific Model Development 6:373-388, DOI 10.5194/gmd-6373-2013

Vanniere B, Guilyardi E, Madec G, Doblas-Reyes FJ, Woolnough S (2013) Using seasonal hindcasts to understand the origin of the equatorial cold tongue bias in CGCMs and its impact on ENSO. Climate Dynamics pp 963-981, DOI 10.1007/s00382-012-1429-6

Walters DN, Williams KD, Boutle IA, Bushell AC, Edwards JM, Field PR, Lock AP, Morcrette CJ, Stratton RA, Wilkinson JM, Willett MR, Brooks ME, Copsey D, Earnshaw PD, Harris CM, Manners JC, MacLachlan C, Palmer MD, Roberts MJ, Tennant WJ (2015) The Met Office Unified Model Global Atmosphere 6.0/6.1 and JULES Global Land 6.0/6.1.0 congurations. In preparation

Wang B, Fan Z (1999) Choice of South Asian Summer Monsoon Indices. Bulletin of the American Meteorological Society 80(4):629-638 
${ }_{1386}$ Webster PJ, Yang S (1992) Monsoon and ENSO: Selec-

${ }_{1387}$ tively interactive systems. Quarterly Journal of the

${ }_{1388} \quad$ Royal Meteorological Society 118:877-926

1389 Webster PJ, Moore AM, Loschnigg JP, Leben RR

${ }_{1390}$ (1999) Coupled ocean-atmosphere dynamics in the

1391 Indian Ocean during 1997-98. Nature 401:356-360

${ }_{1392}$ Wilks D (2006) Statistical Methods in the Atmospheric 1393 Sciences, 2nd edn. Elsivier Inc.

${ }_{1394}$ Williams KD, Harris CM, Camp J, Comer RE (2015)

1395 The Met Office Global Coupled model 2.0 (GC2) con-

1396 figuration. Geoscientific Model Development Discus-

1397 sions 8:521-565, DOI 10.5194/gmdd-8-521-2015 